\title{
Dynamic compressive behavior of a novel ultra-lightweight cement composite incorporated with rubber powder
}

\author{
Zhenyu HUANG ${ }^{1,2}$, Lili SUI ${ }^{1,2 *}$, Fang WANG ${ }^{1,2}$, Shilin DU², Yingwu ZHOU ${ }^{1,2}$, Jianqiao YE ${ }^{3 *}$ \\ 1 Guangdong Provincial Key Laboratory of Durability for Marine Civil Engineering, Shenzhen University, \\ Shenzhen, China 518060.
}

2 College of Civil and Transportation Engineering, Shenzhen University, Shenzhen, China 518060.

3 Department of Engineering, Lancaster University, Lancaster LA1 4YR, UK

\begin{abstract}
This paper develops a novel rubberized ultra-lightweight high ductility cement composite (RULCC) with added rubber powder and low content PE fiber $(0.7 \%)$, and investigates the dynamic compressive response and failure mechanism of the RULCC both experimentally and analytically. The test program examines the dynamic compressive stress-strain relationship of the RULCC through Split Hopkinson Pressure Bar (SHPB) impact tests. The results show that the rubber powder aggregates have significant effect on the compressive strength, stress-strain relations and failure mechanism of the RULCC. A volume replacement of fine aggregates with $5 \%, 10 \%$ and $20 \%$ rubber power results in a reduction in static compressive strength by $29.5 \%$, $47.7 \%$ and $60.3 \%$, respectively. The RULCC with a low fiber content of $0.7 \%$ in volume exhibits a $3 \%$ direct tensile strain, and a $4-5 \%$ tensile strain can still be achieved after $10 \%$ rubber powder is added to the RULCC, showing a high ductility of the material. The SHPB impact test shows that the compressive strength increases with strain rate. An empirical model, taking into account of the replacement ratio of the rubber powder aggregates in the RULCC, is developed in this paper to evaluate the Dynamic Increasing Factor (DIF). The experimental and analytical studies are essential to better understand the fundamental dynamic behavior of the RULCC for its further applications in engineering applications, such as protective structures, etc.
\end{abstract}

Keywords: Rubberized concrete; Cement composite; Lightweight Concrete; Split Hopkinson Pressure Bar.

* Corresponding author. Tel: +86 755-86975402; Fax: +86 755-26732850; Emails: suill@ szu.edu.cn; j.ye@ @lancaster.ac.uk 


\section{Introduction}

2 Concrete using lightweight aggregates, such as expanded clay/shale [1], fly ash aggregates [2], fly

3 ash cenospheres [3, 4], perlite [5], pumice [6], are classified as Lightweight aggregate concrete

4 (LWAC). As summarized in Huang et al [4], LWAC has an apparent density of less than, e.g.,

$52000 \mathrm{~kg} / \mathrm{m}^{3}$ with a compressive strength of $8-80 \mathrm{MPa}, 1950 \mathrm{~kg} / \mathrm{m}^{3}$ with a compressive strength of

$610-38.5 \mathrm{MPa}$ and $1850 \mathrm{~kg} / \mathrm{m}^{3}$ with a compressive strength of $17-35 \mathrm{MPa}$, respectively, as specified

7 in JGJ 51-2002 [7], CEB-FIP 2010 and BS EN 13055-2016 [8,9], ACI 213R-14 and ASTM C330

$8[10,11]$. Lightweight aggregates mainly reduce self-weight and improve thermal performance of

9 concrete [12, 13]. LWAC can be used in industrial and building structures to reduce structural

10 weight and the materials used in construction. LWAC also reduces the transportation and hoisting

11 cost during construction, the gravity load on the foundation, thus the reinforcement and labor cost

12 [1-6, 12-15]. Due to the superior performance of LWAC, it has been used in, e.g., bridges [16],

13 prefabricated construction [17] and offshore structures [18]. To further reduce the self-weight of

14 offshore structures, Huang et al. [3, 4], Chia et al. [19] and Wu et al. [20] developed a novel ultra-

15 lightweight cement composite (ULCC) using fly ash cenospheres. The apparent density of the

16 ULCC is only $1450 \mathrm{~kg} / \mathrm{m}^{3}$ with a 28 -day compressive strength of $60 \mathrm{MPa}$. To further downsize the

17 design, they developed a novel steel-ULCC-steel sandwich composite [21], and studied the

18 bending, shearing, compression and dynamic impact resistance of beams, plates, shells and walls

19 made of the sandwich composite experimentally and theoretically [15,18,21-24]. A set of design

20 methods were also proposed. The above studies have demonstrated that the ULCC has obvious

21 advantages, though the brittleness of the ULCC has limited its wider applications.

22 With the rapid development of the global economy and the automobile industry, the annual

23 increase of waste tires over the world is currently about $8 \%$ to $10 \%$. It is estimated that by 2020 ,

* Corresponding author. Tel: +86 755-86975402; Fax: +86 755-26732850; Emails: suill@ szu.edu.cn; j.ye@ @lancaster.ac.uk 
24 the output of waste tires in China will reach 20 million tons, which has become an emerging issue

25 of environmental concerns. Traditional landfill and incineration not only cause huge

26 environmental pollution, but also are energy inefficient. In 1996, Fedroff et al. [25] pioneered in

27 producing rubberized concrete by mixing rubber powder made from grinding waste tires, which

28 offered a new approach to recycle waste tires and started a new research topic on rubberized

29 concrete. Many studies have since shown that, compared with the ordinary concrete, rubberized

30 concrete has good resistance to crack and abrasion and energy dissipation capacity [26-34]. As an

31 elastomer, rubber aggregates in concrete can restrain the generation and development of cracks,

32 thus improve the energy dissipation capacities of concrete $[25,26]$. However, adding rubber may

33 reduce compressive strength, flexural strength and workability of concrete. To achieve improved

34 energy dissipation, while still maintain sufficient material strength, adding additional mineral

35 admixture such as silica fume and steel or polypropylene fibers are considered as commonly used

36 and effective methods [27, 29, 37]. Nili et al. [28] conducted drop hammer impact tests on hooked

37 steel fiber reinforced concrete with or without silica fume using the test method specified in ACI

38544 [35]. The impact resistance of the concrete with $1 \%$ steel fiber and silica fume was twenty

39 times higher than that of the plain concrete and 2.4 times higher than that of the concrete with

40 silica fume only. Fiber-bridging plays a significant role in preventing crack and energy dissipating

41 in the damage process. Similar findings were also concluded by Ali et al. [27] and Gupta et al.

42 [29]. Guo et al. [37] reported that steel slag increased the stiffness and brittleness of the concrete

43 in the static and SHPB impact tests. Yoo and Banthia [36] also studied the impact resistance of

44 fiber reinforced concrete. Strain-rate sensitivities of fiber reinforced concretes depend on the types

45 of loading and the strength of matrix. Tensile impacts are more sensitive to strain rate than

46 compressive and flexural impacts are. Higher strength concrete is less sensitive compared to lower 
47 strength concrete. Liu et al. [30] evaluated the impact behavior of rubberized concrete of different

48 rubber particle size and content through Splitting Hopkinson Pressure Bar (SHPB) tests. The

49 results showed that with a fixed content of rubber, the dynamic compressive strength increased as

50 the increase of the rubber particles size. However, when the rubber content exceeded $10 \%$ of the

51 fine aggregate by weight, the energy dissipation capacity of the concrete started to decline.

52 The observations and conclusions made from the previous research have suggested that rubberized

53 concrete is particularly beneficial to structures that require high impact resistance, such as high-

54 rise buildings, long-span bridges, offshore platforms and other mega constructions. Moreover,

55 these structures are normally very heavy due to their large cross sections that require more

56 reinforcement. Thus, lightweight high strength concrete is a compromising alterative due to its

57 unique advantages, such as low density, good thermal insulation and durability [13, 14].

58 Unfortunately, most of the existing lightweight concrete has low strength and is brittle, which has

59 limited their applications. Hence, demands for new lightweight cement-based materials that have

60 high ductility and good energy consumption are increasing. Naturally, using rubber aggregates to

61 replace fine or coarse aggregates can reduce the weight and increase impact resistance, thus have

62 the potential to meet the demand and recycle waste tires at the same time. To the authors' best

63 knowledge, the research on the dynamic responses of rubberized LWAC is rare. The failure

64 mechanism and strain rate sensitivity of the promising material also remain unclear.

65 This paper reports an experimental study on the development of an ultra-lightweight, high ductility

66 cement composite with rubber powder and PE fibers. The mechanical properties of the new

67 material, such as compressive strength, elastic modulus and damage modes under different strain

68 rates are evaluated through static and SHPB impact tests. Furthermore, this paper proposes and

69 validates a modified equation to predict the Dynamic Increasing Factor (DIF) of the new material. 


\section{Experimental Program}

\section{$71 \quad 2.1$ Materials and mix proportion design}

72 To make the novel rubberized ultra-lightweight cement composite (RULCC) mixes, raw materials

73 including cement, fly ash cenospheres (FAC), silica fume, rubber powder aggregate and PE fiber

74 were used. The RULCC was designed to have a target 28-day compressive strength of around

$7535 \mathrm{MPa}$ with low density of around $1450 \mathrm{~kg} / \mathrm{m}^{3}$. Fig. 1 shows the fine aggregates and their particle

76 size distribution. The fine aggregate was FAC with a specific gravity of $870 \mathrm{~kg} / \mathrm{m}^{3}$, a fineness

77 modulus of $0.902 \mathrm{~g} / \mathrm{cm}^{3}$ and an average size of $20-300 \mu \mathrm{m}$. The binder consisted of $100 \%$ of CEM

78 I 52.5R ordinary Portland cement and $11 \mathrm{wt} \%$ of silica fume and $38.7-48.4 \mathrm{wt} \%$ of FAC. The size

79 of the rubber powder was $380 \mu \mathrm{m}$, which was used to replace the FAC. A volume replacement of

80 FAC with $5 \%, 10 \%, 15 \%$ and $20 \%$ rubber power were selected in the test. The water absorption

81 of the rubber, which was surface treated, was less $1 \%$. A picture of the rubber powder is shown in

82 Fig. 1(b). To make a workable cement composite, a high-water reducing agent, polycarboxylate-

83 based superplasticizer (SP) was used. The surface of the PE fibers was coated with hydrophilic.

84 The mechanical properties of the PE fibers are shown in Table 2. The mix proportions are divided

85 into seven groups as listed in Table 1, which includes mixtures with 5 different rubber replacement

86 ratios $(0 \%, 5 \%, 10 \%, 15 \%$ and $20 \%$ by volume of FAC), and 2 different fiber content ( $0 \%$ and

$87 \quad 0.7 \%$ by volume).

88 Before casting, the slump flow of all the mixtures was measured based on ASTM C1611 as shown

89 in Fig. 2. Good fluidity was maintained in all composites, but rubber particles had a negative effect

90 on the fluidity of fresh ULCC. The specimens were demoulded after $24 \mathrm{~h}$ curing at room

91 temperature and were cured then in a standard fog room (temperature $20 \pm 2^{\circ} \mathrm{C}$ and moisture ratio

$9295 \%$ ) until the test day. 


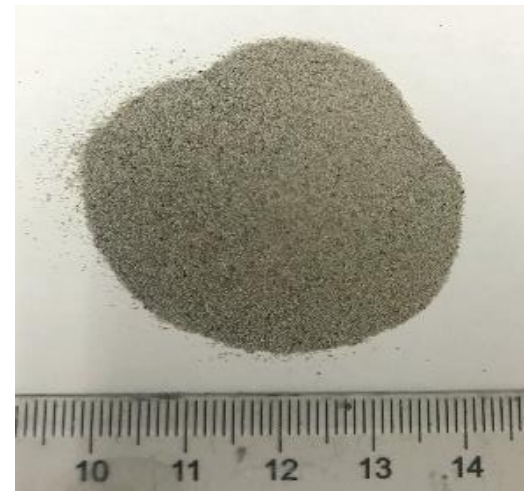

(a) Fly ash cenospheres (FAC)

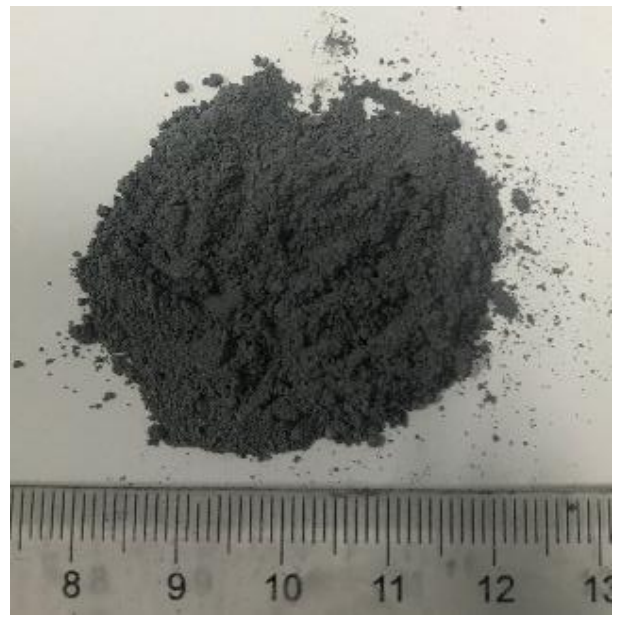

(c) Silica fume

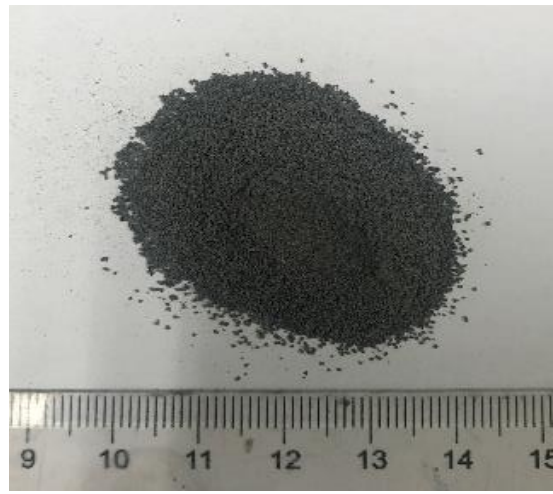

(b) Rubber powder

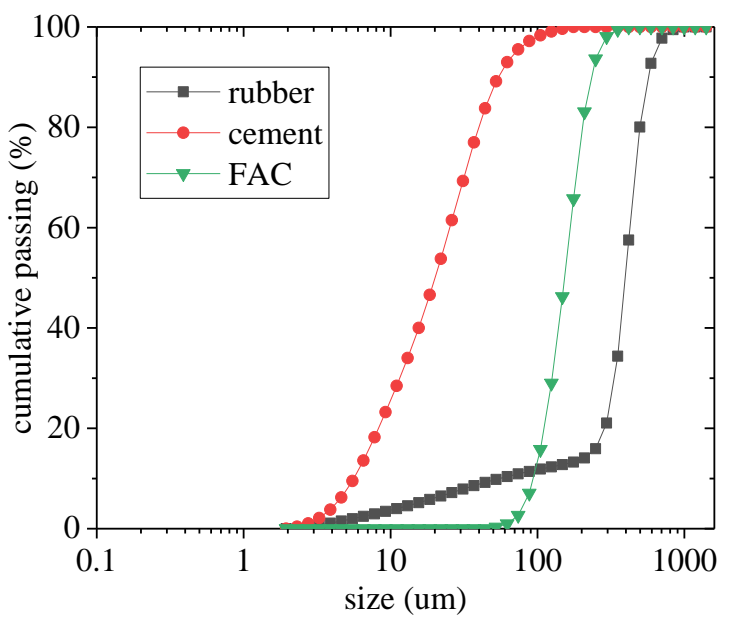

(d) Particle size distribution of raw materials

Figure 1 Fine aggregates and particle size distribution

93

94
Table 1 Mix proportions of RULCC (by weight)

\begin{tabular}{ccccccccc}
\hline Mix ID & $\begin{array}{c}\text { Ce- } \\
\text { ment }\end{array}$ & SF & FAC & Rubber & Water & SP & SRA & Fiber \\
\hline R0-0 & 1 & 0.11 & 0.484 & 0.000 & 0.37 & 0.001 & 0.001 & 0 \\
R5-0 & 1 & 0.11 & 0.460 & 0.027 & 0.37 & 0.001 & 0.001 & 0 \\
R10-0 & 1 & 0.11 & 0.436 & 0.054 & 0.37 & 0.001 & 0.001 & 0 \\
R15-0 & 1 & 0.11 & 0.412 & 0.080 & 0.37 & 0.001 & 0.001 & 0 \\
R20-0 & 1 & 0.11 & 0.387 & 0.107 & 0.37 & 0.001 & 0.001 & 0 \\
R0-0.7PE & 1 & 0.11 & 0.484 & 0.000 & 0.37 & 0.001 & 0.001 & $0.7 \%$ \\
R10-0.7PE & 1 & 0.11 & 0.436 & 0.054 & 0.37 & 0.001 & 0.001 & $0.7 \%$ \\
\hline
\end{tabular}

95 Note: $\mathrm{SF}=$ silica fume; FAC=fly ash cenospheres; $\mathrm{SP}=$ superplasticizer; SRA= shrinkage reducing agent.

96 R10-0.7PE represents the RULCC with $10 \%$ rubber powder replacement of FAC and $0.7 \%$ PE fiber by volume. 


\begin{tabular}{cccccc}
\hline $\begin{array}{c}\text { Diameter } \\
(\mu \mathrm{m})\end{array}$ & Length $(\mathrm{mm})$ & $\begin{array}{c}\text { Density } \\
\left(\mathrm{g} / \mathrm{cm}^{3}\right)\end{array}$ & $\begin{array}{c}\text { Tensile } \\
\text { strength }(\mathrm{MPa})\end{array}$ & $\begin{array}{c}\text { Elastic mod- } \\
\text { ulus }(\mathrm{GPa})\end{array}$ & $\begin{array}{c}\text { Fracture elon- } \\
\text { gation }(\%)\end{array}$ \\
\hline 24 & 12 & 0.97 & 3000 & 120 & $2-3$ \\
\hline
\end{tabular}

100

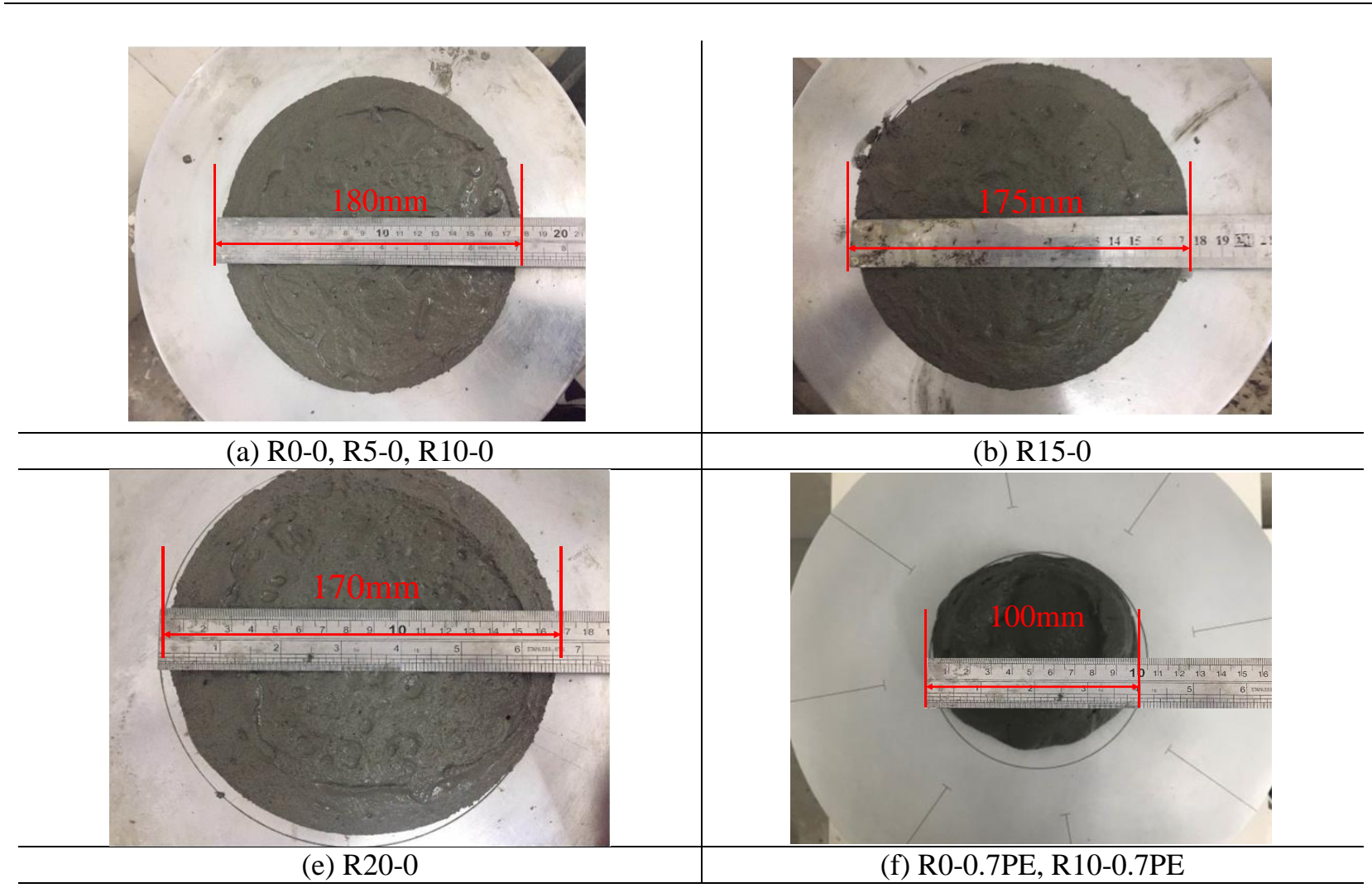

Figure 2 Slump flow for typical RULCC

\subsection{Test instrumentation and loadings}

102 The static compression test was performed by using 300 tone MTS machine on a $\Phi 100 \times 200$

103 cylinders, according to ASTM C39/C39M-01 (2014) [38]. Uniaxial static tensile test was carried

104 out in accordance with the standard recommended by JSCE [39]. For each design mix, three

105 concrete samples were prepared for the tests. Figure 3 shows the typical instrumentation for the

106 compressive and tensile tests.

107 Scanning Electron Microscope (SEM) was conducted to observe the microscopic morphology of

108 the RULCC using Quanta TM 250 FEG equipped with field emission environmental scanning

109 mirror. The samples were taken from the central part of the broken pieces of the matrix without 
110 polishing process. Before scanning, the sample surfaces to be observed were gold coated and

111 treated for conductivity.

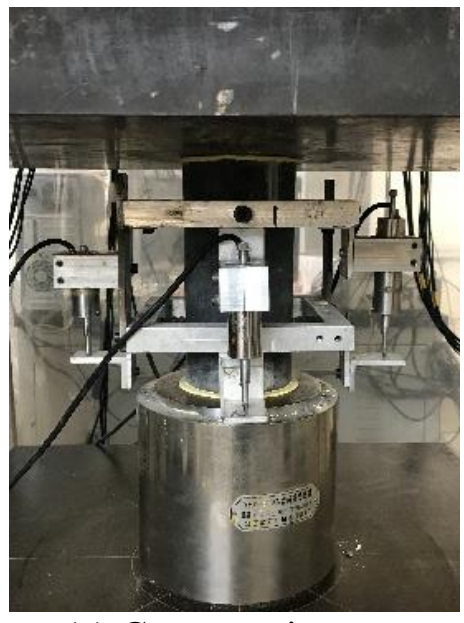

(a) Compressive test
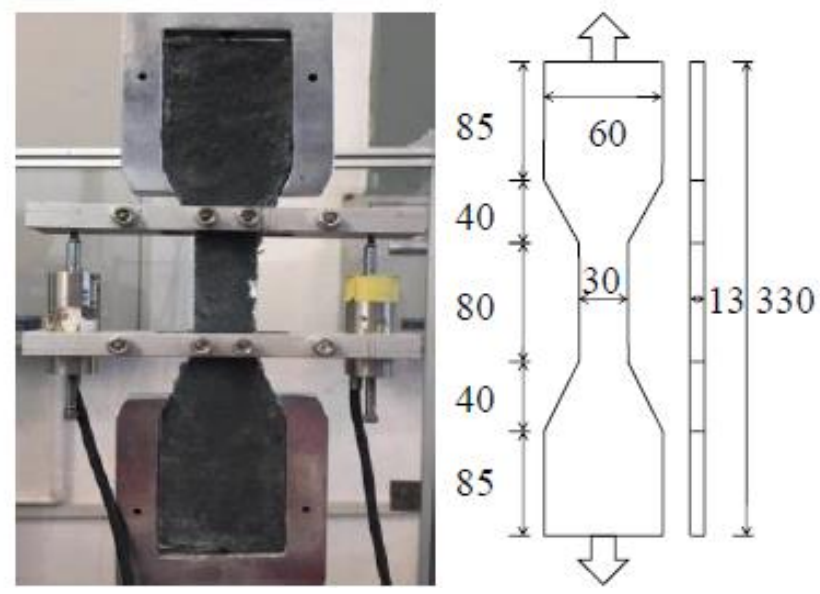

(b) Tensile test

Figure 3 Static test instrumentation for RULCC

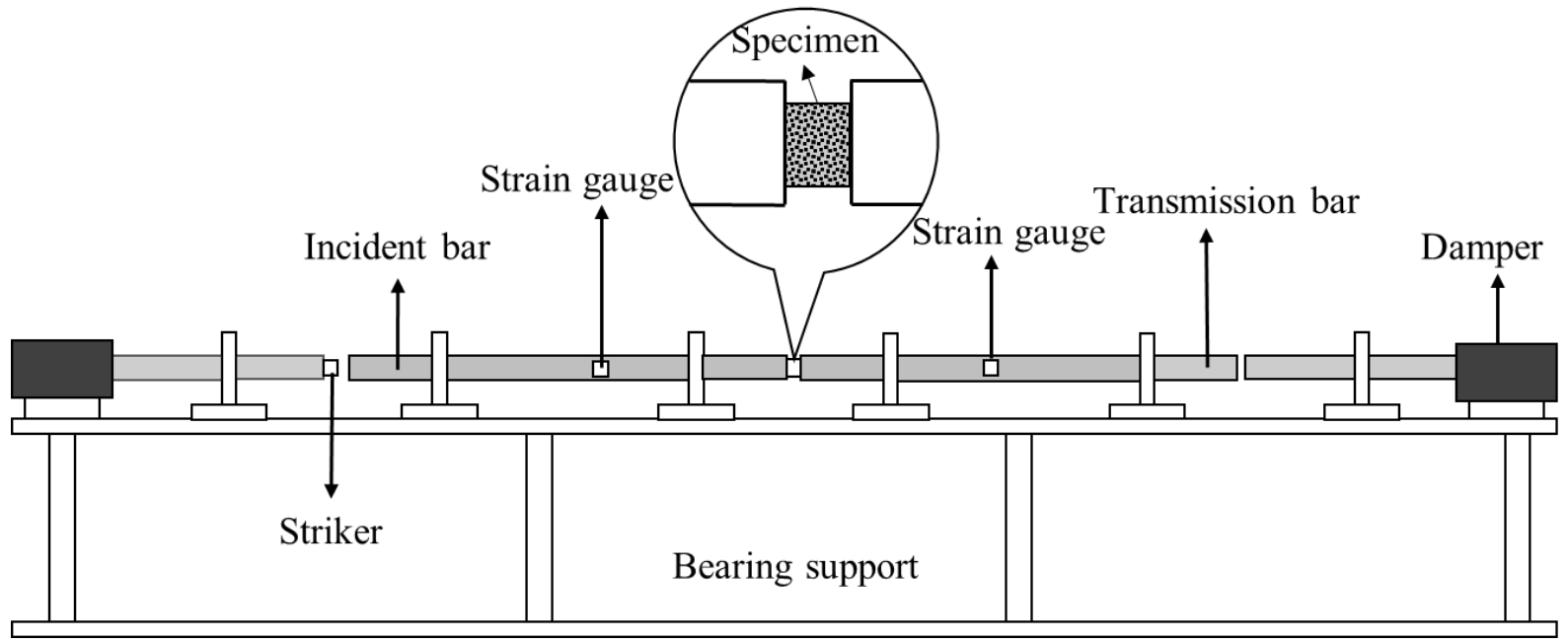

(a) Configuration of SHPB 


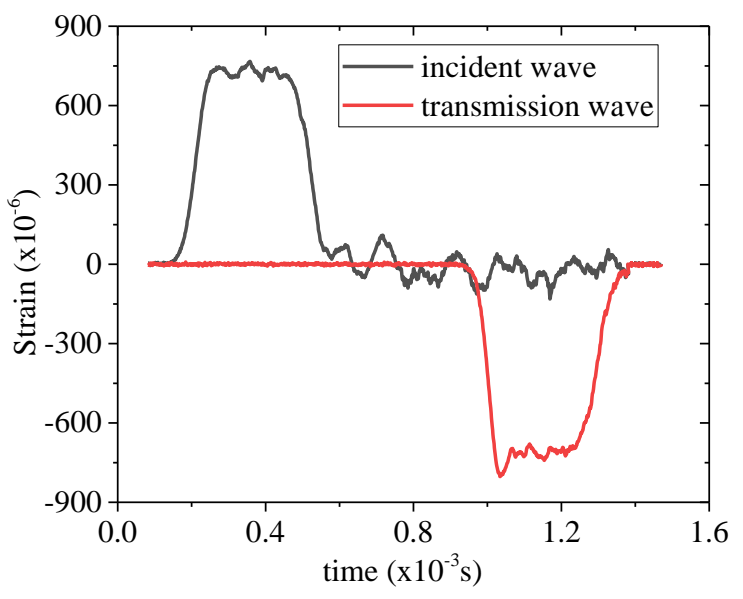

(b) Strain waveform for empty bar

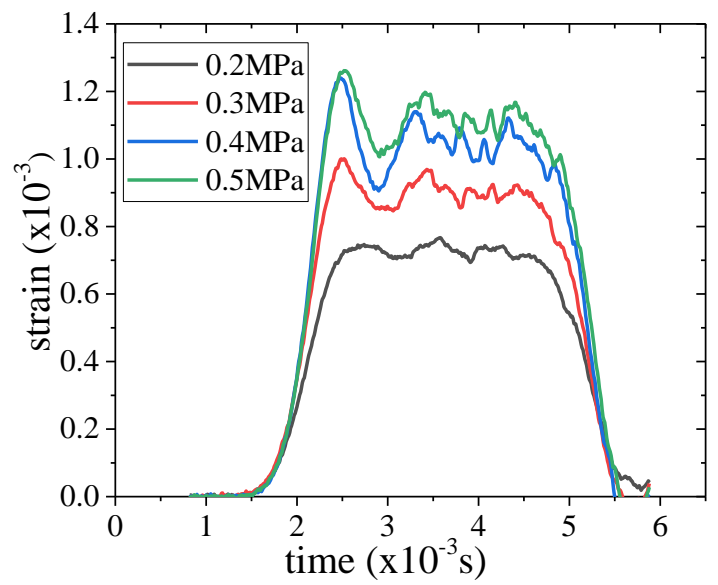

(c) Strain waveform under different pressure

Figure 4 SHPB test and impact waveform input

112 For the dynamic tests, SHPB tests were performed to investigate the dynamic behavior of the

113 RULCC. For each strain rate, five concrete samples were tested, the results of which were averaged

114 then to obtain the stress-strain curves, impact velocity, peak strain and peak stress, etc. SHPB test

115 was first proposed by Hopkinson at the beginning of the last century [40]. The typical test

116 configuration, consisting of a striker bar, an incident bar, a transmission bar, a damper and the

117 specimen to be tested, is shown in Figure 4 (a). SHPB test is mainly based on the following two

118 basic assumptions: (1) the stress pulse propagation is one-dimensional, and (2) the stress across

119 the length of the specimen is uniform. Hypothesis (1) assumes that the strain measured by the

120 strain gauge on the bar surface is identical to the strain on the end surface of the specimen,

121 representing a uniform state of stress. Hypothesis (2) assumes that the effect of stress wave can be

122 ignored, so that the specimen deforms uniformly under the uniform stress. The mechanical

123 properties of the tested material can be characterized by the average stress and the average strain

124 of the specimen obtained from the deformation of the bar. Figure 4(b) shows a classic waveform

125 input. Based on the above two assumptions, the stress-strain relations of the specimens can be

126 calculated by Eqs. (1)-(3), 


$$
\sigma=\frac{A_{0}}{A_{s}} E_{0} \varepsilon_{t}(t)
$$

$$
\varepsilon=-2 \frac{C_{0}}{L_{s}} \int_{0}^{t} \varepsilon_{r}(t) d t
$$

$$
\dot{\varepsilon}=-2 \frac{C_{0}}{L_{s}} \varepsilon_{r}(t)
$$

130 where, $A_{0}$ and $A_{s}$ are, respectively, the cross section area of the bar and the specimen; $E_{0}$ and $C_{0}$

131 are the respective elastic modulus and elastic wave velocity of the rod; $L_{s}$ is the length of the

132 specimen; $\varepsilon_{t}(\mathrm{t})$ and $\varepsilon_{r}(\mathrm{t})$ are the transmission wave and the reflection wave in the bar, respectively.

133 The impact rod of the SHPB used for the dynamic compressive test in this paper has a diameter of

$134120 \mathrm{~mm}$. The strain wave recorded from an empty test is shown in Figure 4(c) and the basic

135 parameters of the SHPB for Eqs.(1-3) can be found in Table 3.

136 In order to control the flatness of the end surface of the specimens and reduce the friction effect of

137 the contact surface between the bar and the concrete samples, a special grinding machine was used

138 to prepare the concrete samples. The seven groups of specimens were subjected to four different

139 strain rates relative to four different air pressures, i.e., $0.2 \mathrm{MPa}, 0.3 \mathrm{MPa}, 0.4 \mathrm{MPa}$ and $0.5 \mathrm{MPa}$

140 respectively. These pressures would induce the strain rates of 90/s to 190/s as mentioned in Section

141 3.3.3. The selected strain rates are the reprehensive rates of typical impacts, i.e., vehicle impact,

142 ship impact and blast impact, which may occur to bridges, offshore platforms and military

143 protective structures.

144

Table 3 Parameters for SHPB

\begin{tabular}{ccccc}
\hline$A_{0} /\left(\mathrm{mm}^{2}\right)$ & $A_{s} /\left(\mathrm{mm}^{2}\right)$ & $E_{0} /(\mathrm{GPa})$ & $C_{0} /(\mathrm{m} / \mathrm{s})$ & $L_{s} /(\mathrm{mm})$ \\
\hline 11309.7 & 7854.0 & 206 & 5100 & 50
\end{tabular}




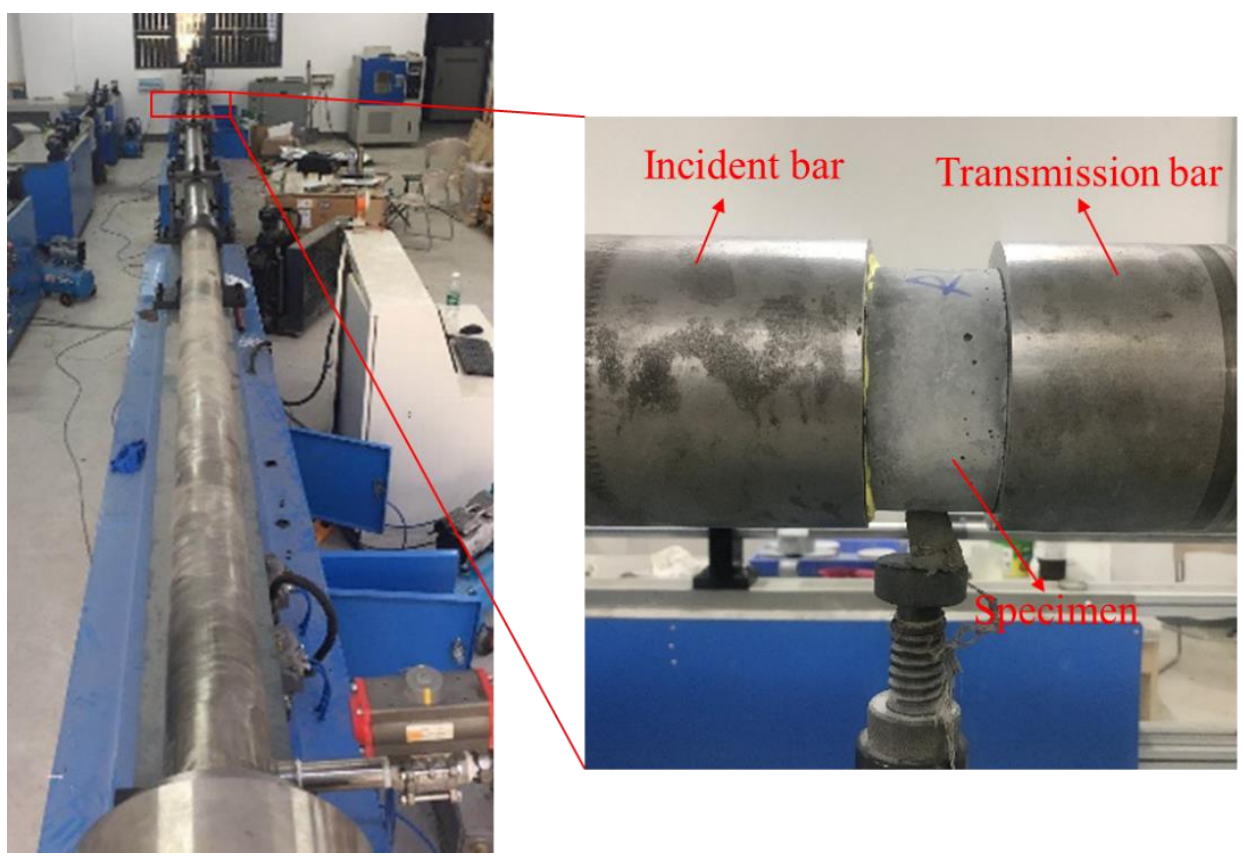

Figure 5 Split Hopkinson Pressure Bar and test sample

\section{3. Test Results and Discussions}

\section{$147 \quad$ 3.1 Static compressive test}

148 The compressive strength of the RULCC decreases with the increase of rubber powder content.

149 The compressive strength decreases by $29.5 \%, 47.7 \%, 54.8 \%$ and $60.3 \%$, respectively, when $5 \%$,

$15010 \%, 15 \%$ and $20 \%$ of the fine aggregates in the composites were replaced by rubber powder 151 without fiber, as shown in Fig.6. As an organic polymer material, rubber powder has weak 152 adhesion with cement based inorganic materials, resulting in a reduction of strength in the 153 interfacial transition zone (ITZ). Each rubber particle distributed in the cement composites 154 represent a weak spot that may initiate micro cracks and reduce compressive strength of the cement 155 composites further. Similar finding was also reported by Liu et al. [30]. The elastic modulus of 156 rubber is much lower than that of cement composite, leading to larger deformation of the rubber 157 powder under quasi-static loading. The elastic modulus of the RULCC is much lower than that of 158 normal concrete because of the lower elastic modulus of FAC and absence of coarse aggregates. 159 It was found that the elastic modulus of the RULCC decreased by $15.7 \%, 29.3 \%, 32.1 \%$ and $33.6 \%$, 160 respectively, when 5\%,10\%, $15 \%$ and $20 \%$ of the fine aggregates were replaced by rubber. Fig. 1617 (a) illustrates the morphology of the rubber powder and the FAC in the cracked composites using 162 SEM. It is shown that the FACs are distributed uniformly in the cement composite, showing a 163 good composite workability. There is no evidence of composite segregation in this test as reported 
164 in the previous tests that the lightweight FAC may float on the cement grout if segregation occurs

165 [20]. Fig.7(b) is the image of a spalled composite with failure initiated from the ITZ between the

166 rubber particles and the cement composite. The crack passed through this ITZ due to the weak

167 bond strength. Without adding rubber powder, however, the specimen appeared to break and flake

168 with a clear sound heard when it was crushed. Due to the larger deformation of rubber, the

169 fragments of the specimens with rubber powder are larger than those from the specimens without

170 added rubber. This observation indicates that the rubber powder reduces the brittleness of the

171 ULCC. The addition of PE fibers to the R0-0 and R10-0 groups (R0-0.7PE and R10-0.7PE)

172 reduces the compressive strength by $16.7 \%$ and $8.8 \%$, respectively. This reduction may be

173 attributed to that additional air bubbles are introduced during the mixing process as PE fibers are

174 dispersed in the cement composites. Compared to the normal rubberized concrete [26], the RULCC

175 has a greater reduction in compressive strength, mainly due to the following two factors: (1)

176 Rubber aggregates are used to replace fine aggregate such as sand in normal concrete. However,

177 in this test, the replacement ratio of rubber powder is proportional to the total aggregate volume,

178 resulting in a larger replacement ratio than that of the normal rubberized concrete [29]; (2) The

179 size of aggregate particles is normally within $0-10 \mathrm{~mm}$ in normal concrete, which fills the pores to

180 make the concrete more compact. However, the rubber powder has a maximum size of $380 \mu \mathrm{m}$ in

181 this test, which is comparable to that of FAC (maximum size of $300 \mu \mathrm{m}$ ), leading to less compact

182 microstructure in the composite. In this case, cracks initiate from the ITZ that causes lower

183 compressive strength. Future study should be conducted to investigate the effect of particle size of

184 rubber powder. 


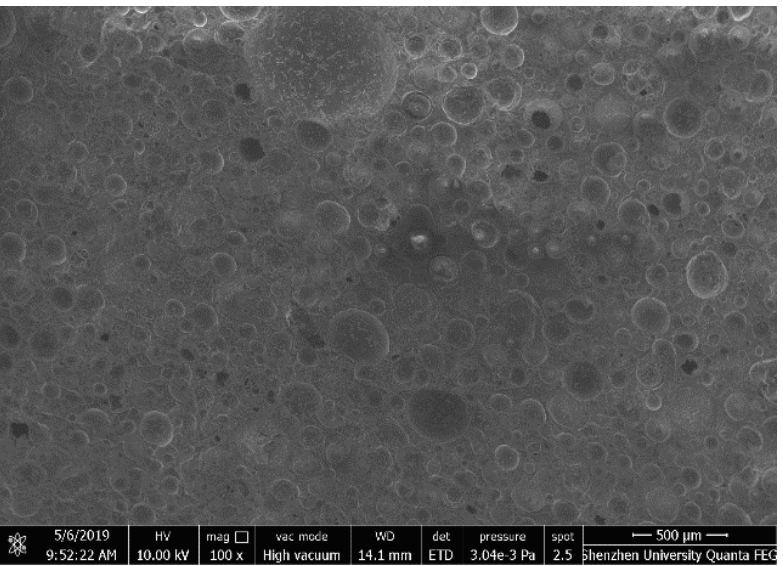

(a) Morphology of the composites

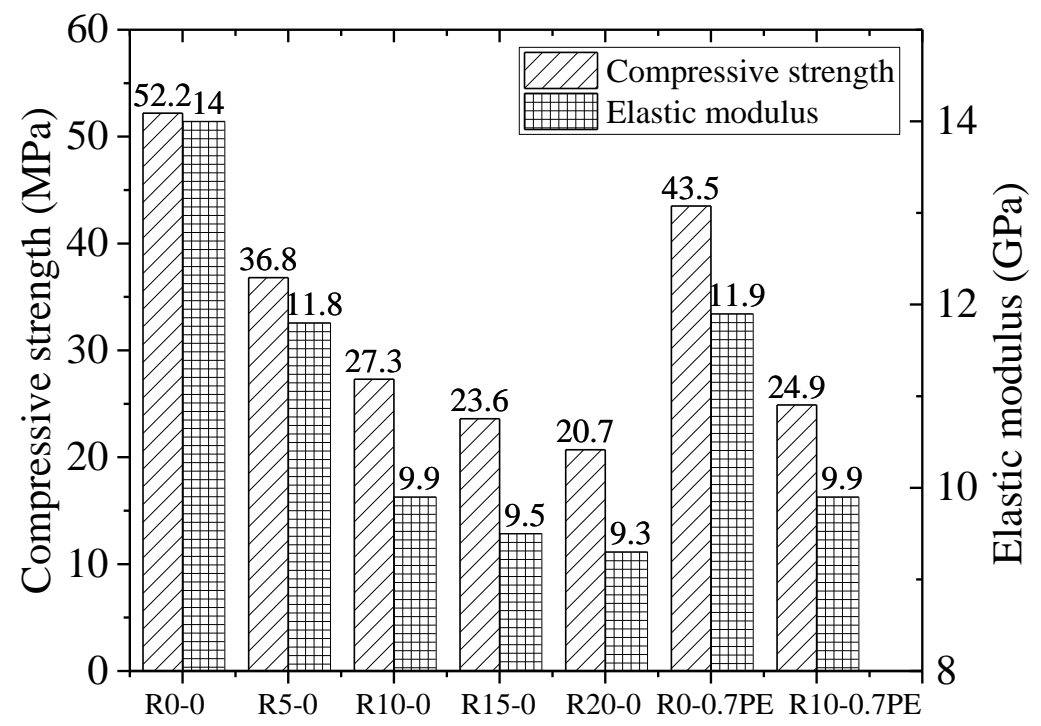

Figure 6 Compressive strength and elastic modulus of different RULCC mix

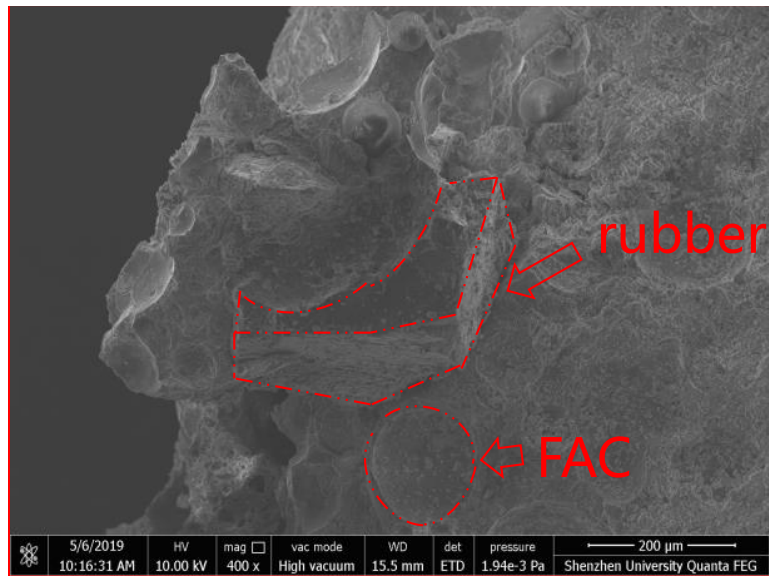

(b) Morphology of rubber powder and FAC in composites

Figure 7 SEM Morphology

$188 \quad 3.2$ Static tensile test

189 Figure 8 shows the direct tensile stress-strain curves of the RULCC coupon specimens. It is found

190 that the tensile strain capacity of R0-0.7PE with low fiber content of $0.7 \%$ can reach $3 \%-4 \%$, which

191 is much higher than that of normal concrete, and meets the tensile strain requirements of the En-

192 gineered Cement Composite (ECC) materials [41]. The tensile strain capacity of R10-0.7PE with

$19310 \%$ rubber powder can reach about 4\%-5\%, showing promising ductile performance. Compared

194 to the conventional ECC with $2 \%$ polymer fibers, RULCC can save $65 \%$ fiber content in volume, 
195 which shows great economic potentials for future applications. Figs. 8 and 9 illustrate the multiple 196 micro cracking behavior of R0-0.7PE and R10-0.7PE, respectively. Based on the failure modes of 197 R0-0.7PE and R10-0.7PE, the first crack appears when the stress reaches the tensile strength of 198 the concrete substrate. The stress declines slightly but the load bearing capacity resumes very 199 quickly due to the bridging effect of the PE fibers. This is followed by the next stage of local 200 failure, leading to a progressive process that results in the formation of multiple fine cracks in the 201 composites [4].

202

203

204

205

\section{3.3 Dynamic compressive test}

207

\subsubsection{Failure modes}
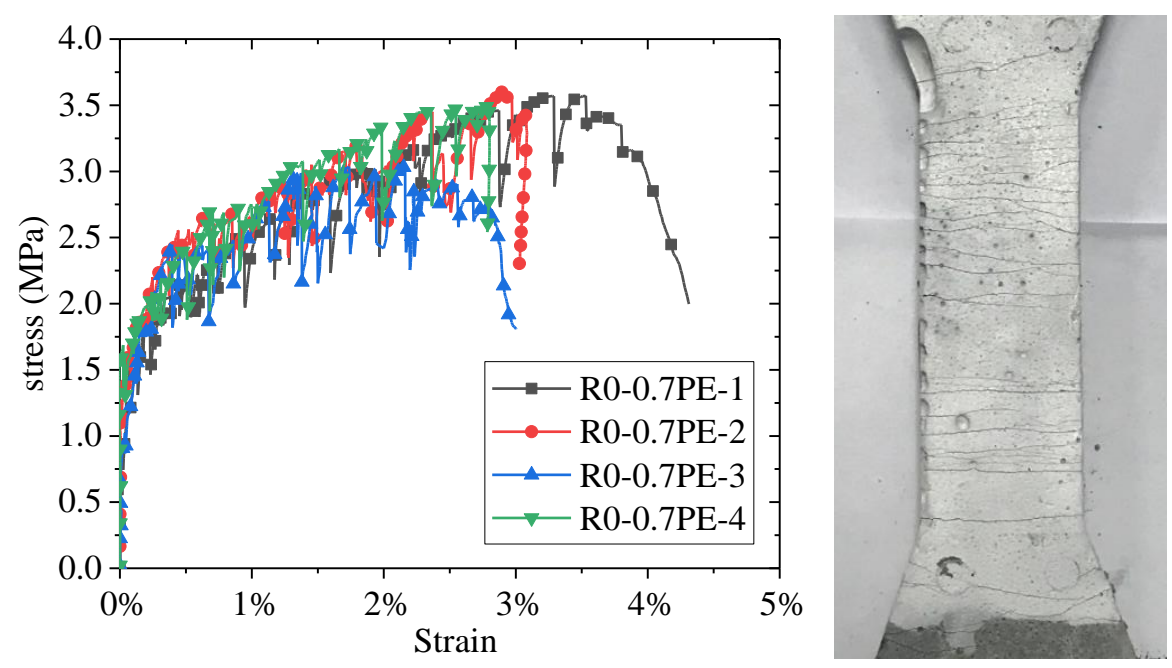

Figure 8 Tensile test of R0-0.7PE
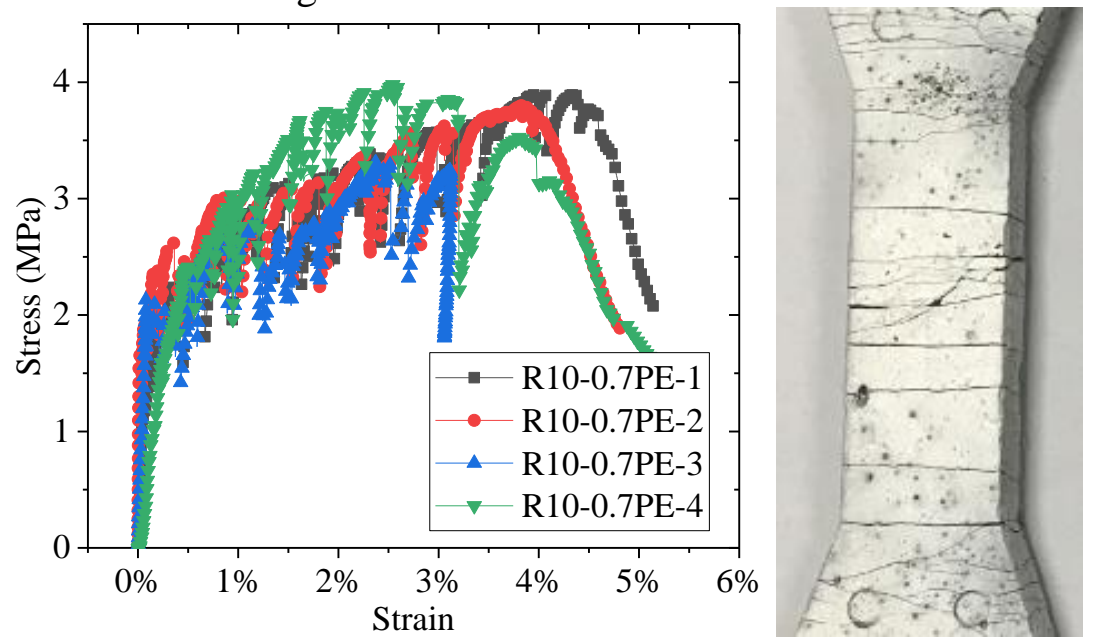

Figure 9 Tensile test of R10-0.7PE 
208 The dynamic impact test on the RULCC was performed by the $120 \mathrm{~mm}$ diameter SHPB. Fig. 10

209 shows the failure modes of each mix group after the impact tests. Within a mix group, a higher

210 strain rate causes more serious damage of the specimens. At the same strain rate, an increase of

211 rubber content results in larger but less cement fragments, especially at a high strain rate, as shown

212 in the comparisons between Figs. 10 (a)-(e). It should be noted that for the static compressive tests,

213 because there are void defects in the composites, the damage is usually initiated from the weakest

214 region to form a crack, leading to the final failure in the composite with only several main cracks.

215 Unlike the static responses discussed previously, the rapid release of the impact energy under a

216 high strain rate impact cannot be completed by the propagation of a single crack as the rate of

217 crack opening is much slower. This delay leads to initiations of multiple cracks until the ultimate

218 fragmentation occurs. After adding rubber powder into the cement composite, kinetic energy can

219 be released more effectively due to the elastic deformation and energy dissipation capacity of rub-

220 ber, thus reduce the number of the cracks with less fragmentation at failure. This observation is

221 more obvious when more rubber is added. When PE fibers are introduced, the fibers tend to

222 "tighten" the surrounding matrix during a low strain rate impact, thus only cracking without frag-

223 mentations are observed, as shown in Figs.10 (f) and (g). At a high strain rate of 146.8-185.1/s,

224 the degree of damage of the rubberized mix group R10-0.7PE is similar to that of the non-rubber-

225 ized group R0-0.7PE. All the specimens show both cracks and fragments and, hence, loss their

226 integrity. The effect in preventing cracking of cement composite using low PE fiber content seems

227 more pronounced than using rubber. However, the R5-0 group exhibits comparable energy dissi-

228 pation capacity to R0-0.7PE, judged by the areas under the stress-strain curves shown in the next 229 section. 


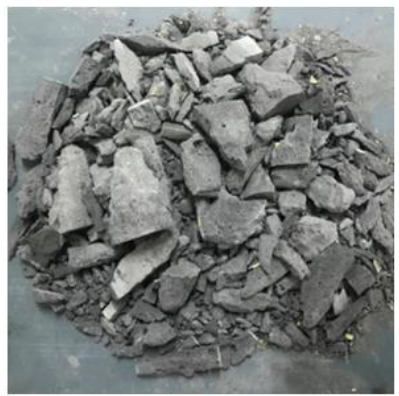

$0.2 \mathrm{MPa}(94.1 / \mathrm{s})$

230

231

232

233

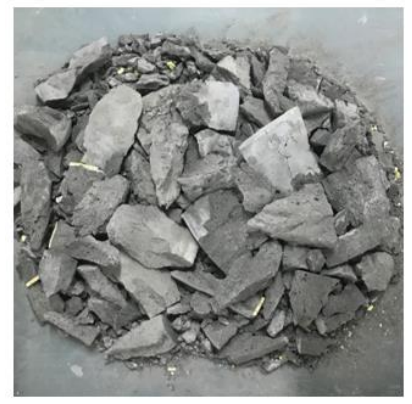

$0.2 \mathrm{MPa}(91.9 / \mathrm{s})$

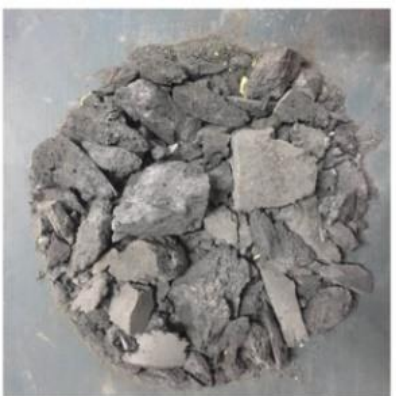

0.2MPa (105.3/s)

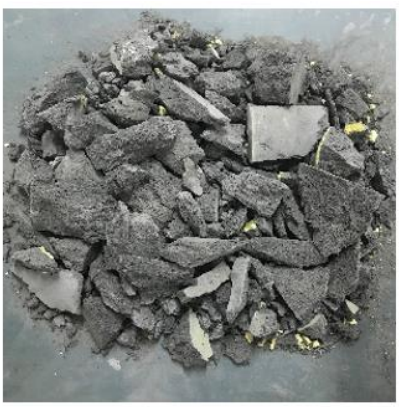

$0.2 \mathrm{MPa}(104.8 / \mathrm{s})$

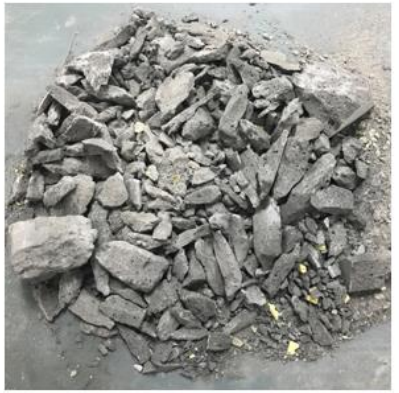

$0.3 \mathrm{MPa}(130.6 / \mathrm{s})$

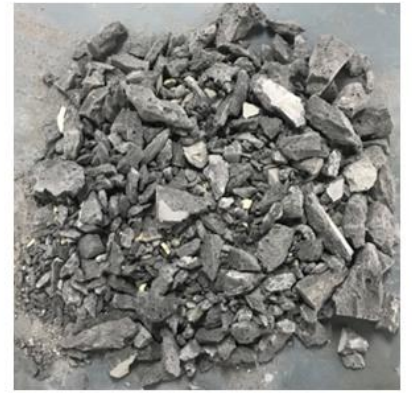

$0.4 \mathrm{MPa}(150.7 / \mathrm{s})$

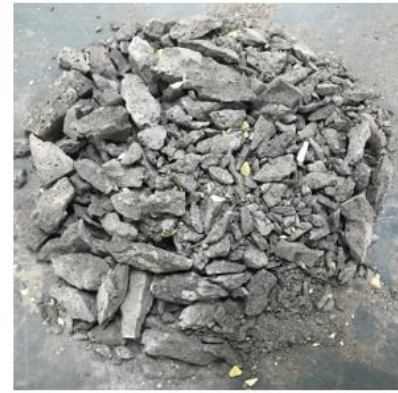

$0.5 \mathrm{MPa}(183.4 / \mathrm{s})$

(a) R0-0

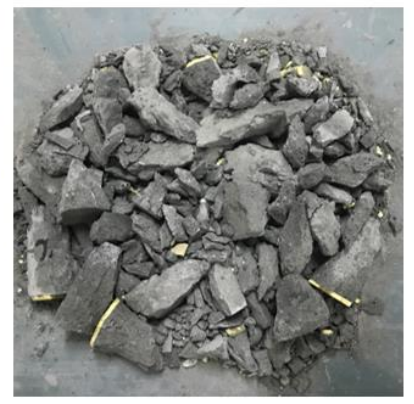

$0.3 \mathrm{MPa}(123.4 / \mathrm{s})$

(b) R5-0

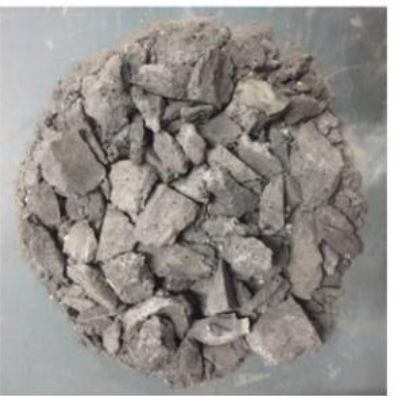

$0.3 \mathrm{MPa}(128.4 / \mathrm{s})$

(c) R10-0

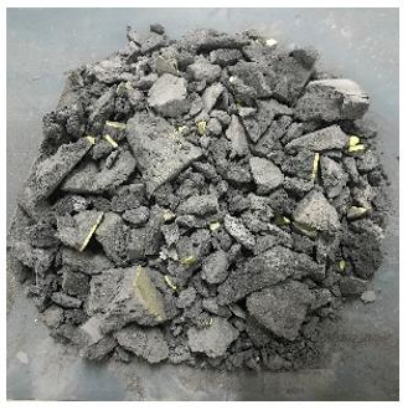

$0.3 \mathrm{MPa}(129.2 / \mathrm{s})$

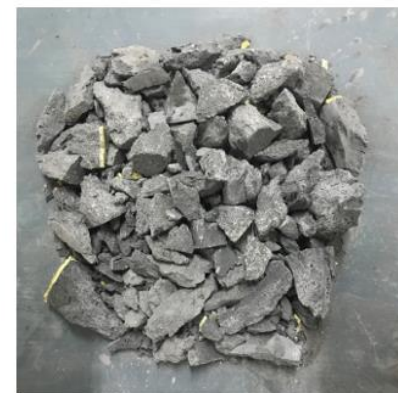

$0.4 \mathrm{MPa}(149.9 / \mathrm{s})$

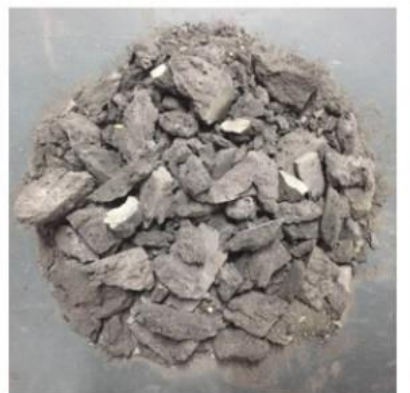

$0.4 \mathrm{MPa}(155.7 / \mathrm{s})$

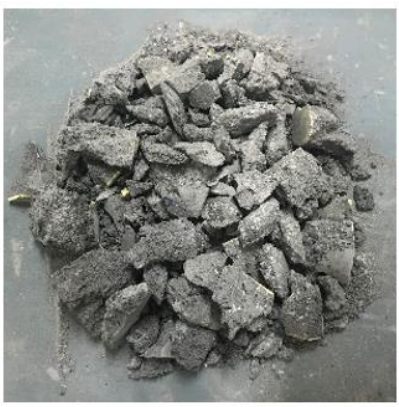

$0.4 \mathrm{MPa}(159.8 / \mathrm{s})$

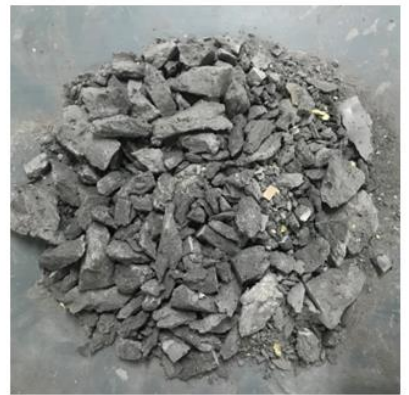

$0.5 \mathrm{MPa}(178.6 / \mathrm{s})$

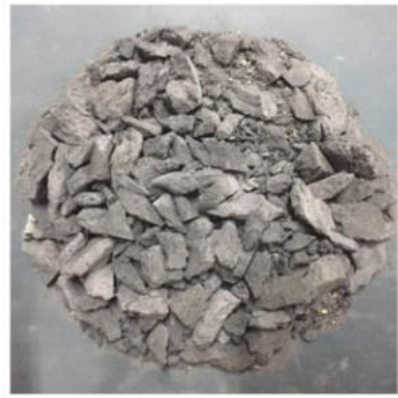

$0.5 \mathrm{MPa}(181.5 / \mathrm{s})$

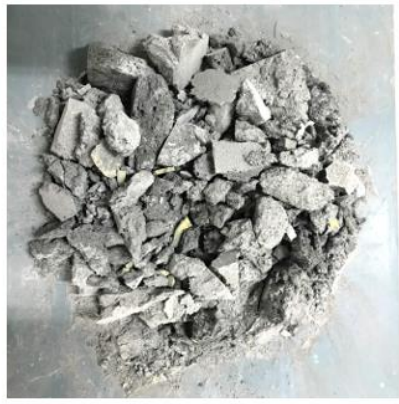

$0.5 \mathrm{MPa}(180.9 / \mathrm{s})$

(d) R15-0 
235

236

237

\section{8}

239

240

241

242

243

244

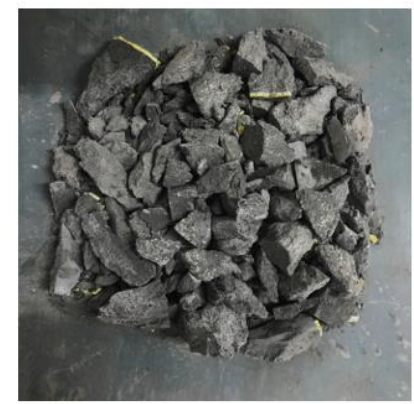

$0.2 \mathrm{MPa}(99.7 / \mathrm{s})$

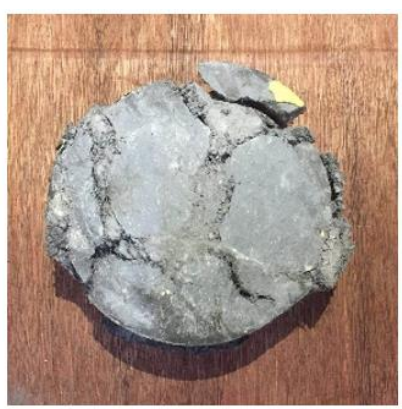

$0.2 \mathrm{MPa}(102.1 / \mathrm{s})$

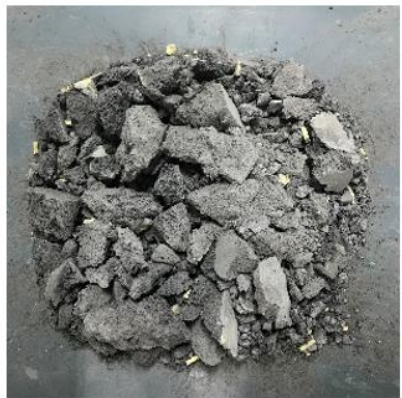

0.3MPa (123.5/s)

(e) R20-0

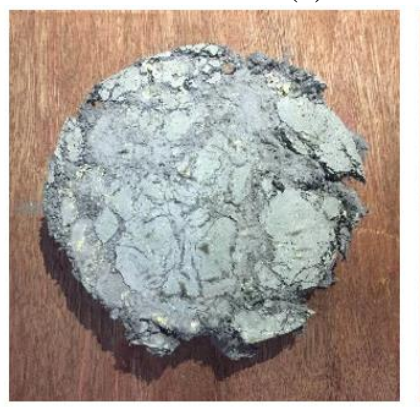

$0.3 \mathrm{MPa}(128.3 / \mathrm{s})$

(f) R0-0.7PE

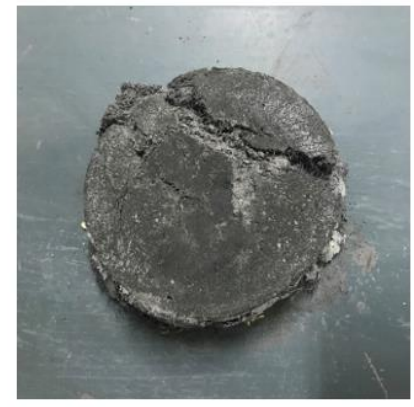

$0.2 \mathrm{MPa}(93.1 / \mathrm{s})$

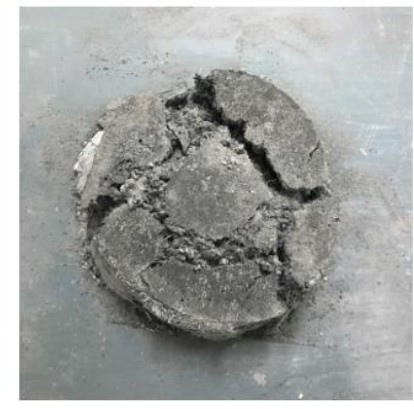

$0.3 \mathrm{MPa}(138.2 / \mathrm{s})$

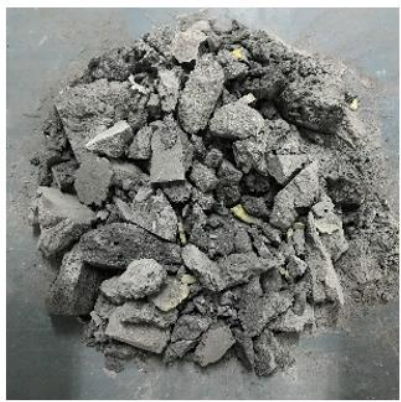

$0.4 \mathrm{MPa}(150.5 / \mathrm{s})$

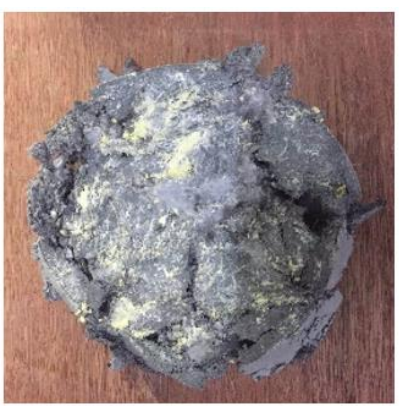

$0.4 \mathrm{MPa}(146.8 / \mathrm{s})$

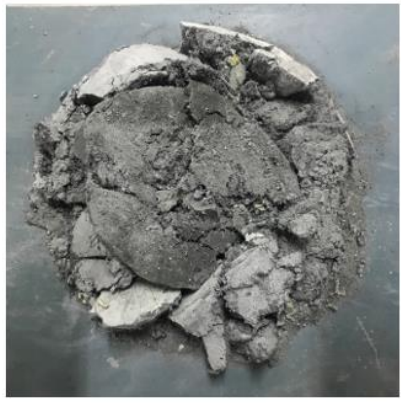

$0.4 \mathrm{MPa}(158.7 / \mathrm{s})$

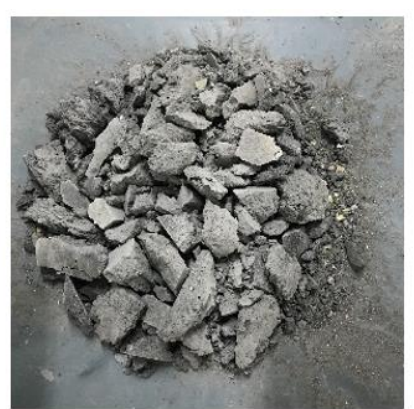

$0.5 \mathrm{MPa}(186.5 / \mathrm{s})$

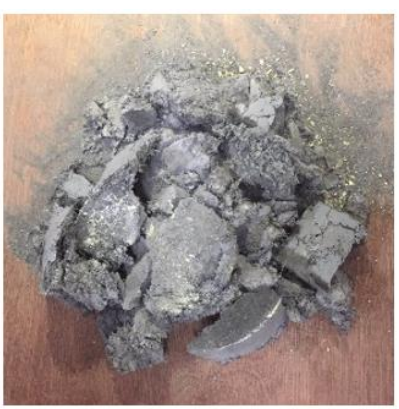

$0.5 \mathrm{MPa}(166.4 / \mathrm{s})$

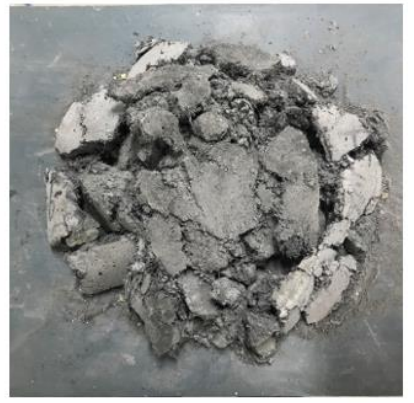

$0.5 \mathrm{MPa}(185.1 / \mathrm{s})$

(g) R10-0.7PE

Figure 10 Failure modes of different mixture under different strain rate

\subsubsection{Dynamic compressive stress-strain curves}

Figure 11 shows the dynamic compressive stress-strain curves of the mix groups under different

strain rates. Comparing Figs.11 (a) and (f), it is found that the stress-strain curves become smoother

when PE fibers are added. Especially in the post-peak stress stage, the enclosed area under the

stress-strain curves is increased, indicating that the addition of an appropriate amount of PE fibers

can improve the dynamic strain capacity and enhance the ductility of the cement composites. This

enhancement is similar to the effect of steel fiber on the concrete under impact loading as presented 
245 by Nili et al. [28]. Table 4 lists the dynamic peak strain and the enclosed area under the dynamic 246 stress-strain curves of the concrete samples. It should be noted that the enclosed area is defined as

247 the integration of the normalized peak stress $\left(\frac{\sigma_{d}}{\sigma_{s}}\right)$ with regard to the strain. Comparing R5-0 with

248 R-0-0.7PE in Table 4, it is found that energy absorption of the cement composite with 5\% rubber

249 powder and no fibers is comparable to that with $0.7 \%$ PE fibers and no rubber. During the impact

250 process, the rubber particles tend to dissipate impact energy due to the large peak strain when the

251 crack propagates to the rubber particles, leading to enhanced deformation capacity of the RULCC

252 and, thus, reduced size of the fragments at failure. Comparing R0-0 with R5-0, the enclosed area

253 under the stress-strain curves increases by $49.6 \%, 78.0 \%, 76.9 \%$ and $39.2 \%$, respectively, for the

254 varying strain rates, and the dynamic peak strain increases by $189 \%, 246 \%$ and 19\%, respectively,

255 when the load pressure increases from $0.3 \mathrm{MPa}$ to $0.5 \mathrm{MPa}$. Compared with the R0-0 group, the

256 added rubber results in an increase in peak stress. The average ratios of the increase are $92.5 \%$,

$25771.6 \%, 81.3 \%$ and $85.8 \%$, respectively, when $5 \%, 10 \%, 10 \%$ and $15 \%$ and $20 \%$ rubber are added,

258 which demonstrates that the peak stress of the composites with rubber is more sensitive to the

259 strain rate compared to those without rubber. However, as the rubber content exceeded $10 \%$ of the

260 FAC by weight, the enclosed area seems to reduce, indicating that the energy dissipation capacity

261 of the RULCC started to decline. This also matches the test results reported by Liu et al. [30].

262 Comparing R0-0 with R0-0.7PE, the addition of PE fibers increases the enclosed area by $22.3 \%$,

$26323.4 \%, 66.0 \%$ and $42.1 \%$, respectively as the strain rate takes $102.1 / \mathrm{s}, 128.3 / \mathrm{s}, 146.8 / \mathrm{s}$ and $166.4 / \mathrm{s}$,

264 which shows that adding PE fibers also has significant effect on energy dissipation. However,

265 when fibers are added into R10-0, the enclosed area is reduced considerably compared to R0-

266 0.7PE. It may be mainly due to the poor bonding strength of the ITZ between the fibers and the

267 cement composite when a significant amount (10\%) of rubber powder are added. Based on the 
analysis of the enclosed area in the dynamic stress-strain curves, a rubber replacement ratio of 5\%-

$26910 \%$ seems to be an appropriate ratio for the RULCC in terms of energy dissipation capacity.

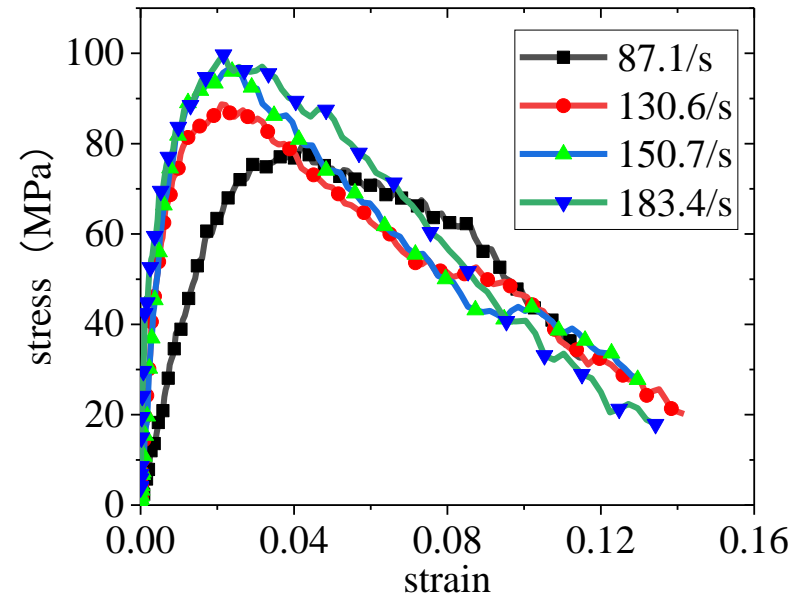

(a) R0-0

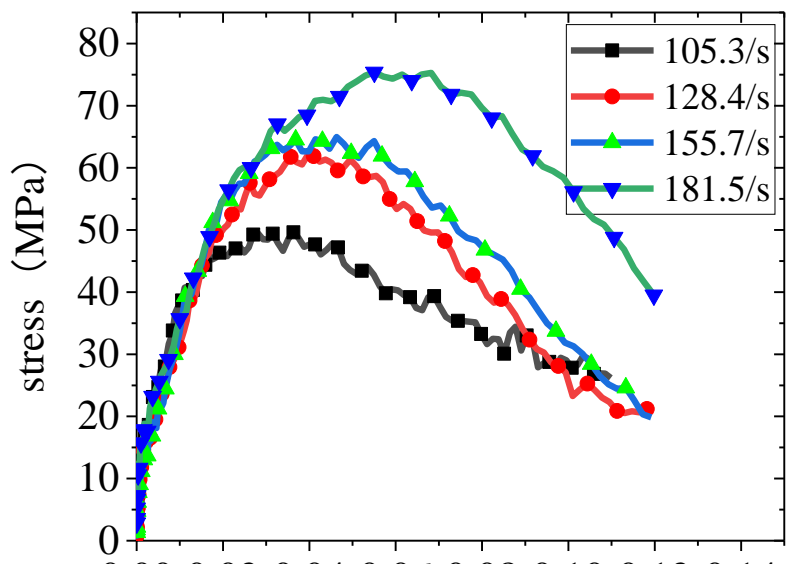

$\begin{array}{llllllll}0.00 & 0.02 & 0.04 & 0.06 & 0.08 & 0.10 & 0.12 & 0.14\end{array}$ strain

(c) R10-0

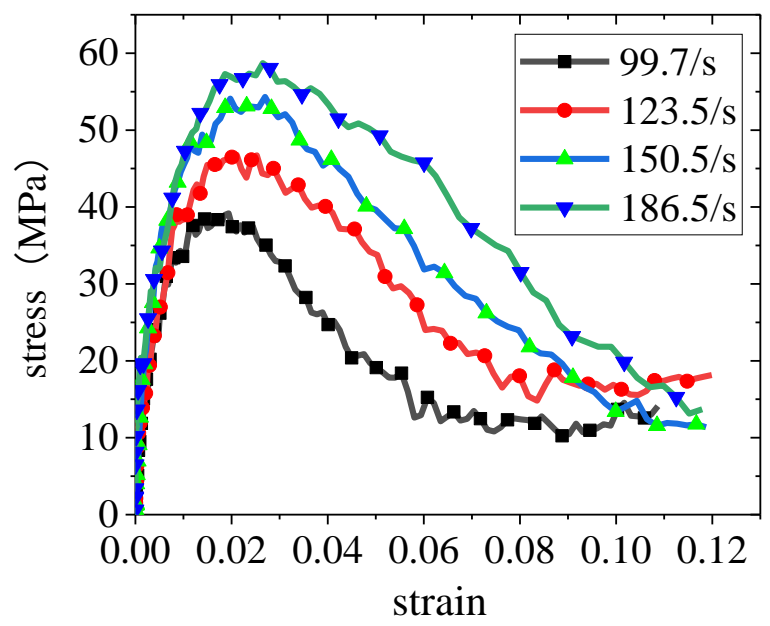

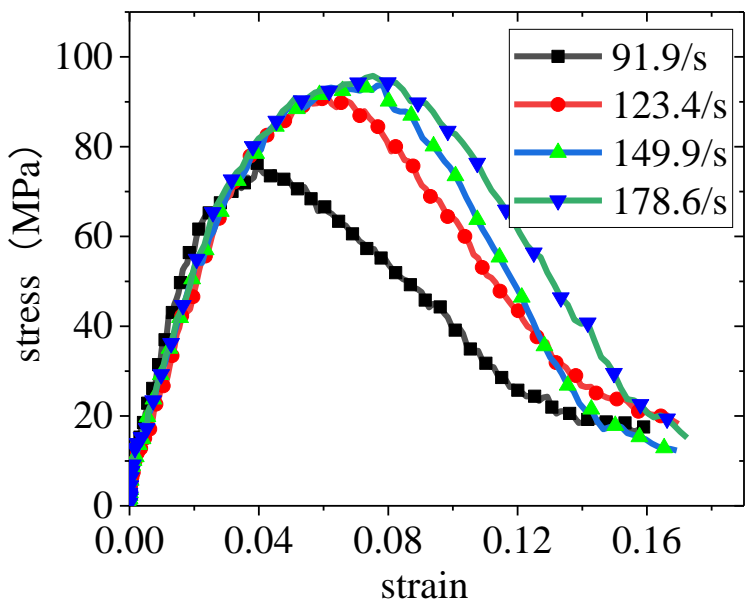

(b) R5-0

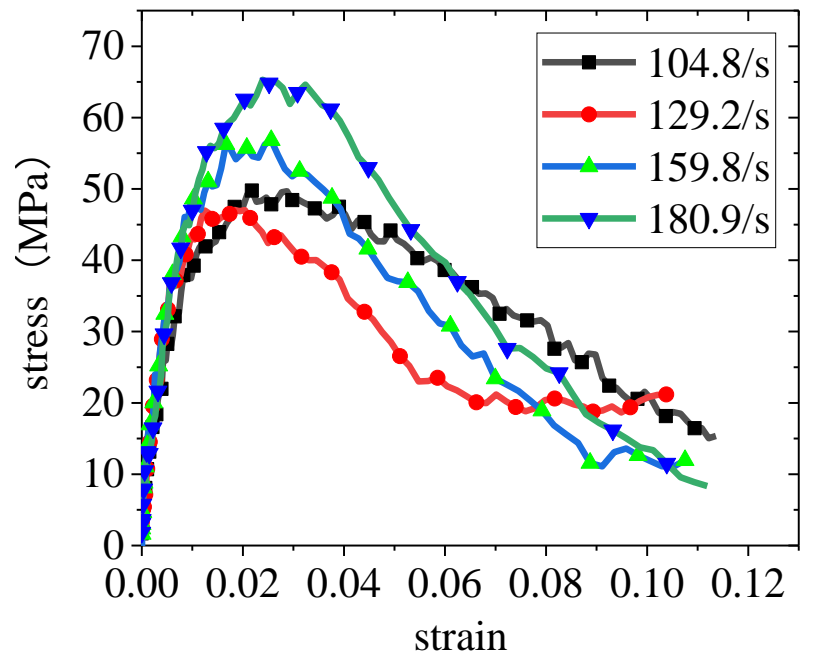

(d) R15-0

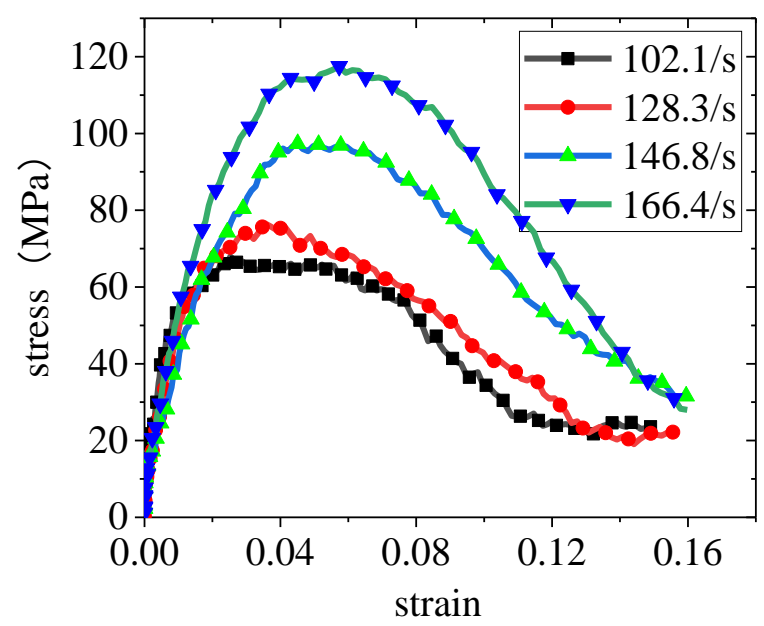

Draft, $4 / 16 / 2020$ 
(e) R20-0

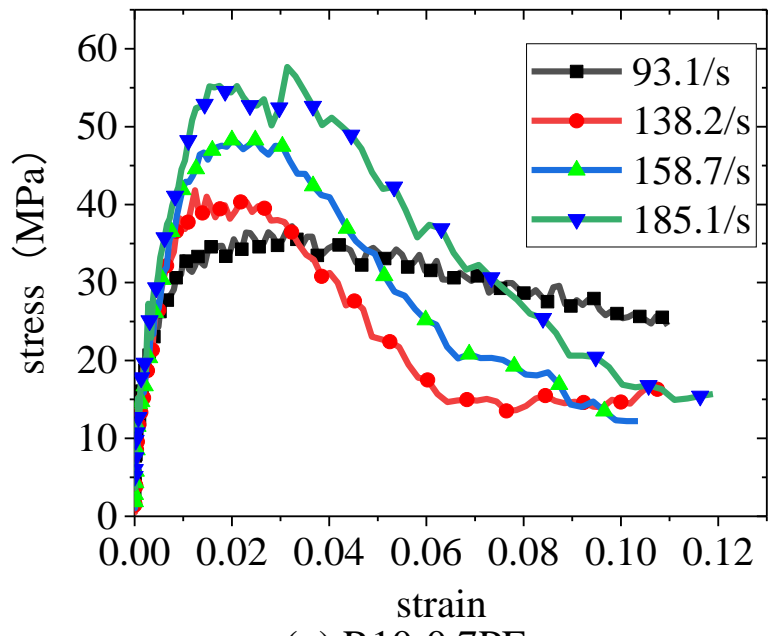

(f) R0-0.7PE

(g) R10-0.7PE

Figure 11 Dynamic compressive stress-strain curves

270

271

\begin{tabular}{|c|c|c|c|c|c|c|}
\hline MIX ID & $\begin{array}{l}\text { Static compres- } \\
\text { sive strength } \\
(\mathrm{MPa})\end{array}$ & $\begin{array}{l}\text { Impact veloc- } \\
\text { ity }(\mathrm{m} / \mathrm{s})\end{array}$ & $\begin{array}{l}\text { Strain rate } \\
\quad(/ \mathrm{s})\end{array}$ & $\begin{array}{l}\text { Dynamic peak } \\
\text { stress (MPa) }\end{array}$ & $\begin{array}{c}\text { Dynamic } \\
\text { peak strain }\end{array}$ & $\begin{array}{c}\text { Enclosed area } \\
\text { of stress-strain } \\
\text { curve }\end{array}$ \\
\hline \multirow{4}{*}{ R0-0 } & \multirow{4}{*}{52.2} & 8.3 & 94.1 & $79.7(52.7 \% *)$ & $4.298 \%(8.6 \#)$ & 1.29 \\
\hline & & 10.3 & 130.6 & $88.7(69.9 \%)$ & $2.112 \%(3.7)$ & 1.41 \\
\hline & & 12.3 & 150.7 & $96.4(84.7 \%)$ & $2.267 \%(4.0)$ & 1.47 \\
\hline & & 13.0 & 183.4 & $100.8(93.1 \%)$ & $6.320 \%(13.0)$ & 2.09 \\
\hline \multirow{4}{*}{ R0-0.7PE } & \multirow{4}{*}{43.5} & 8.7 & 102.1 & $68.0(56.3 \%)$ & $2.527 \%(4.6)$ & 1.58 \\
\hline & & 10.9 & 128.3 & $76.3(75.4 \%)$ & $3.601 \%(7.0)$ & 1.74 \\
\hline & & 12.5 & 146.8 & $97.3(123.7 \%)$ & $4.510 \%(9.0)$ & 2.44 \\
\hline & & 14.0 & 166.4 & $117.5(170.1 \%)$ & $5.734 \%(11.7)$ & 2.97 \\
\hline \multirow{4}{*}{ R5-0 } & \multirow{4}{*}{36.8} & 8.4 & 91.9 & $76.3(107.3 \%)$ & $3.948 \%(7.8)$ & 1.93 \\
\hline & & 10.5 & 123.4 & $91.2(147.8 \%)$ & $6.104 \%(12.6)$ & 2.51 \\
\hline & & 12.2 & 149.9 & $93.7(154.6 \%)$ & $7.838 \%(16.4)$ & 2.60 \\
\hline & & 13.6 & 178.6 & $95.8(160.3 \%)$ & $7.527 \%(15.7)$ & 2.91 \\
\hline \multirow{4}{*}{ R10-0 } & \multirow{4}{*}{27.3} & 8.2 & 105.3 & $49.6(81.7 \%)$ & $3.633 \%(7.1)$ & 1.52 \\
\hline & & 10.7 & 128.4 & $62.1(127.5 \%)$ & $3.964 \%(7.8)$ & 1.84 \\
\hline & & 12.0 & 155.7 & $65.0(138.1 \%)$ & $4.631 \%(9.3)$ & 2.01 \\
\hline & & 13.7 & 181.5 & $74.6(173.3 \%)$ & $5.506 \%(11.2)$ & 3.05 \\
\hline \multirow{4}{*}{ R10-0.7PE } & \multirow{4}{*}{24.9} & 8.7 & 93.1 & $37.4(50.2 \%)$ & $3.236 \%(6.2)$ & 1.35 \\
\hline & & 10.7 & 138.2 & $41.9(68.3 \%)$ & $1.242 \%(1.8)$ & 1.03 \\
\hline & & 12.4 & 158.7 & $48.3(94.0 \%)$ & $2.002 \%(3.4)$ & 1.23 \\
\hline & & 13.8 & 185.1 & $57.6(131.3 \%)$ & $3.140 \%(6.0)$ & 1.67 \\
\hline \multirow{4}{*}{$\mathrm{R} 15-0$} & \multirow{4}{*}{23.6} & 8.5 & 104.8 & $49.4(109.3 \%)$ & $2.644 \%(4.9)$ & 1.70 \\
\hline & & 10.6 & 129.2 & $50.3(113.1 \%)$ & $4.567 \%(9.1)$ & 1.76 \\
\hline & & 12.3 & 159.8 & $56.8(140.7 \%)$ & $2.561 \%(4.7)$ & 1.35 \\
\hline & & 13.6 & 180.9 & $65.3(176.7 \%)$ & $2.391 \%(4.3)$ & 1.70 \\
\hline
\end{tabular}




\begin{tabular}{|c|c|c|c|c|c|c|}
\hline \multirow{4}{*}{ R20-0 } & \multirow{4}{*}{20.7} & 8.0 & 99.7 & $40.8(97.1 \%)$ & $1.938 \%(3.3)$ & 1.08 \\
\hline & & 10.4 & 123.5 & $46.8(126.1 \%)$ & $2.107 \%(3.7)$ & 1.60 \\
\hline & & 12.1 & 150.5 & $53.7(159.4 \%)$ & $2.696 \%(5.0)$ & 1.83 \\
\hline & & 13.6 & 186.5 & $57.4(177.3 \%)$ & $2.650 \%(4.9)$ & 2.18 \\
\hline
\end{tabular}

$272 *$, \#:the value in the bracket represents the increasement ratio compared to the static value.

\section{$273 \quad$ 3.3.3 Effect of strain rate}

274 Figure 12 shows the relationships between the strain rate and the dynamic increasing factor (DIF)

275 for normal concrete, conventional rubberized concrete, ULCC and the RULCC subjected to dy-

276 namic load. It is evident that the RULCC is more sensitive to the strain-rate on the dynamic com-

277 pressive strength compared to the normal concrete, normal rubberized concrete and ultra-light-

278 weight concrete. Similar to the observations from the previous investigations $[26,30,31]$, the

279 strength of concrete increases with the increase of strain rate. In this paper, different load pressure

$280(0.2 \mathrm{MPa}, 0.3 \mathrm{MPa}, 0.4 \mathrm{MPa}$ and $0.5 \mathrm{MPa})$ with respective strain rates of $91.9 \sim 105.3 / \mathrm{s}$,

281 123.4 138.2/s, 149.9 159.8/s, 166.4 186.5/s are considered. By plotting the relationship between

282 the DIF and strain rate in Fig 13, it can be found that with the increase of strain rate, DIF increases

283 approximately linearly with the strain rate. The reason for this is mainly due to the different failure

284 modes and the loading period of the RULCC under different strain rates. The static compression

285 failure originates from micro-cracks in the weak regions and propagation of them to form one or

286 several major cracks, while the dynamic compression failure is due to a large number of micro-

287 cracks generated simultaneously. In principle, the development of concrete cracks can consume a

288 large amount of energy, especially with a high strain rate. A higher velocity impact always gener-

289 ates more micro-cracks that consume more energy. In the process of dynamic compression failure,

290 the formation and propagation of cracks require significant energy. Generally, a higher loading 
291 rate inevitably leaves less time for the material to consume energy through generating and devel292 oping cracks, or store energy through deformation. Thus, an increase of stress is obvious due to 293 the strain-rate effect.

294 Figure 13(a) shows the effect of strain rate on the dynamic compressive strength of the RULCC.

295 For the strain rate of 91.9-186.5/s, the dynamic compressive strength of all the mixes increase 296 approximately linearly as the strain rate increases. However, the strength of R0-0.7PE increases 297 significantly when the strain rate is greater than $146.8 / \mathrm{s}$. This indicates that the PE fiber may have 298 significant effect on the gain in dynamic compressive strength since cracks in the composites may 299 interact with inclined fibers that often lead to fiber bridging and improved fracture resistance.

300 Composites with flexible PE fibers may undergo strain hardening and absorb more impact energy

301 in the loading process, while this effect is not pronounced for other RULCC groups with rubber 302 powder.

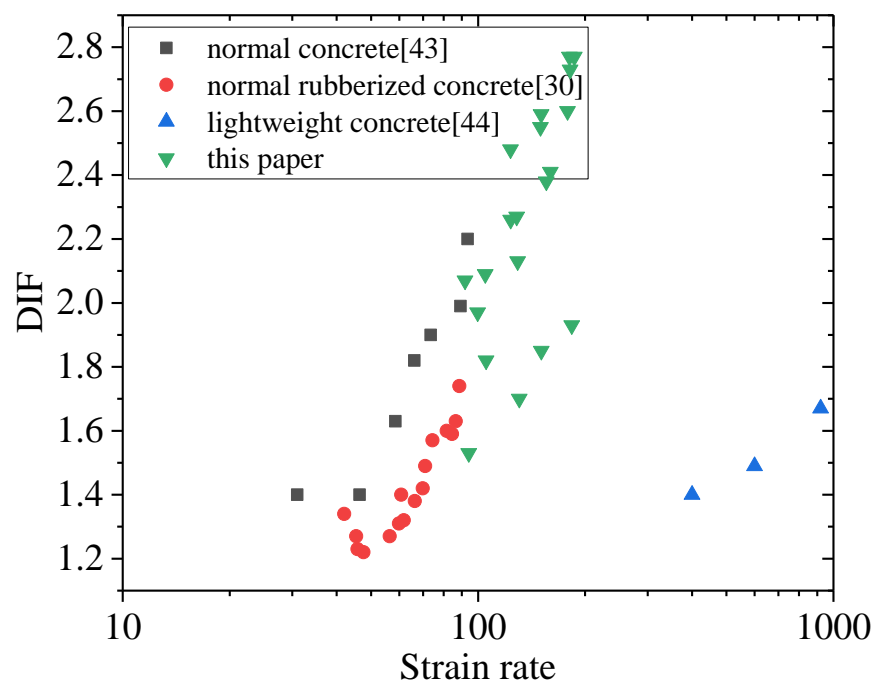

Figure 12. DIF of different types of concrete 


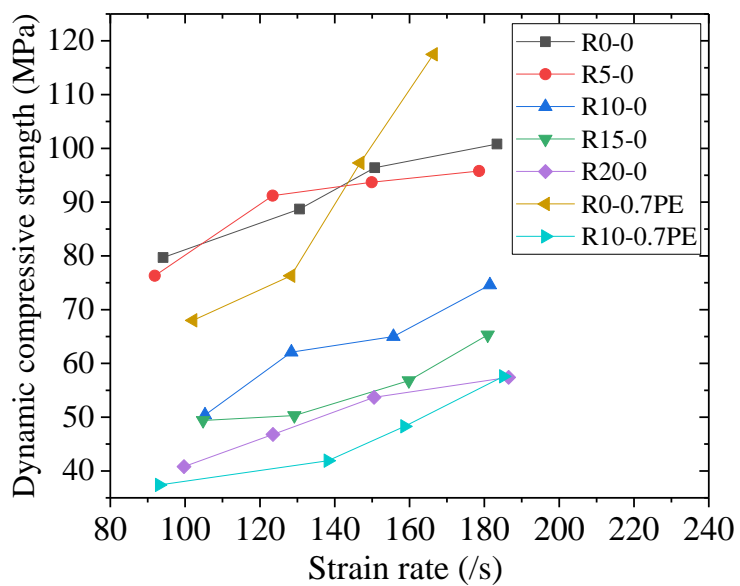

(a) Compressive strength under varying strain rates

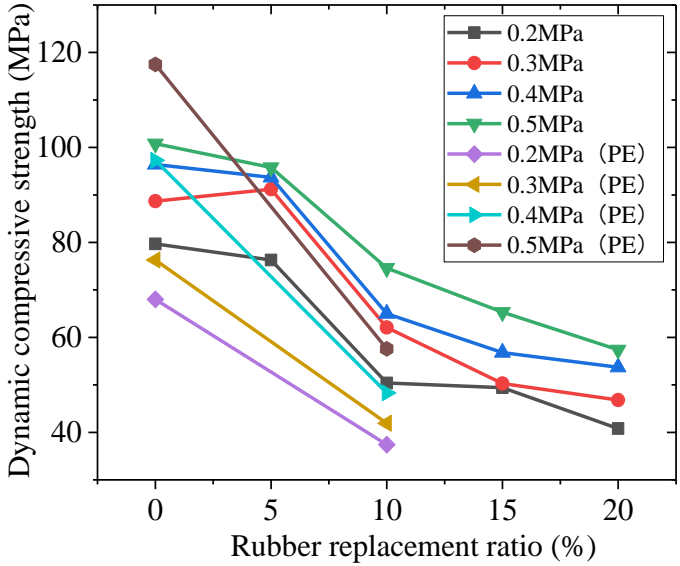

(b) Compressive strength with different amount of rubber powder

Figure 13. Effect of strain rate and rubber replacement ratio

314 the DIF of normal concrete with respect to the strain rate. Chen [26] also proposed a formula to

315 calculate the DIF for the conventional rubberized concrete while Ngo et al. [42] proposed a for-

316 mula to predict the DIF for the high strength concrete. The abovementioned formulas are summa-

317 rized in Table 5. 
Table 5 Existing DIF model in the references

\begin{tabular}{|c|c|c|c|c|}
\hline References & Concrete type & & DIF formulae & \\
\hline CEB-FIP [8] & Normal concrete & $D I F=\frac{\sigma_{d}}{\sigma_{s}}=$ & $=\left\{\begin{array}{l}\left(\frac{\dot{\varepsilon}_{\mathrm{c}}}{\dot{\varepsilon}_{s}}\right)^{0.014} \\
0.012\left(\frac{\dot{\varepsilon}_{\mathrm{c}}}{\dot{\varepsilon}_{\mathrm{s}}}\right)^{\frac{1}{3}}\end{array}\right.$ & $\begin{array}{l}\dot{\varepsilon}_{d} \leq 30 \mathrm{~s}^{-1} \\
\dot{\varepsilon}_{d}>30 \mathrm{~s}^{-1}\end{array}$ \\
\hline
\end{tabular}

\begin{tabular}{|c|c|c|c|}
\hline Chen [26] & $\begin{array}{l}\text { Conventional } \\
\text { rubberized con- } \\
\text { crete }\end{array}$ & \multicolumn{2}{|c|}{$\begin{array}{c}D I F=\frac{\sigma_{d}}{\sigma_{s}}=0.9079\left(\dot{\varepsilon}_{d}\right)^{0.3158} \gamma \quad \dot{\varepsilon}_{d}>30 s^{-1} \\
\log \gamma=6.156 \alpha-0.492 \\
\alpha=\left(5+3(101.6-1.85 R) \% f_{c u} / 4\right)^{-1}\end{array}$} \\
\hline Ngo et al. [42] & $\begin{array}{l}\text { High strength } \\
\text { concrete }\end{array}$ & $\begin{array}{c}D I F=\frac{\sigma_{d}}{\sigma_{s}}=\left(\frac{\dot{\varepsilon}_{d}}{\dot{\varepsilon}_{s}}\right)^{1.026 \alpha} \\
D I F=\frac{\sigma_{d}}{\sigma_{s}}=A \times \ln \dot{\varepsilon}_{d}-B \\
A=-0.0044 \sigma_{s}+0.9866, B=-0 \\
\alpha=1 /\left(20+\sigma_{s}\right) / 2, \dot{\varepsilon}_{1}=0.0022 \sigma_{s}^{2} .\end{array}$ & $\begin{array}{l}\dot{\varepsilon}_{\mathrm{c}}>\dot{\varepsilon}_{1} \\
128 \sigma_{s}+2.1396 \\
0.1989 \sigma_{s}+46.137\end{array}$ \\
\hline $\begin{array}{l}{ }_{*} \sigma_{d} \text { and } \sigma_{s} \text { den } \\
\text { spective dynam } \\
\text { the rubber cont }\end{array}$ & $\begin{array}{l}\text { namic and static } \\
\text { static strain rate } \\
\text { volume fraction }\end{array}$ & $\begin{array}{l}\text { ressive strength, respectively; } \\
\text { s the compressive strength of }\end{array}$ & $\begin{array}{l}\text { and } \dot{\varepsilon}_{s} \text { are the re- } \\
\text { ncrete in } \mathrm{MPa} ; R \text { is }\end{array}$ \\
\hline
\end{tabular}

320 Table 6 gives the predictions of DIF calculated by CEB-FIP [8], Chen's model [26] and Ngo et

321 al.'s model [42] for the RULCC developed in this paper. Obviously, CEB-FIP model overestimates

322 the DIFs when comparing to the test results of the composites without rubber aggregates. Because

323 of the similar brittleness behavior of the high strength and the lightweight concrete, the DIFs pre-

324 dicted by Ngo et al.'s model are close to the test results of R0-0 when no rubber is added to the

325 ULCC. With added rubber, however, the predictions are less accurate. Generally speaking, Chen's

326 model may give scattered predictions of DIFs for the RULCC of this paper since the model was

327 proposed for normal rubberized concrete. By introducing rubber volume to the formula as a pa-

328 rameter, for the low content rubber (R5-0), Chen's model underestimates the DIFs. However, for

329 the high content rubber (R10-0, R15-0 and R20-0), Chen's model overestimates the DIFs. On the 
330 basis of the above work and the test results, modified DIF equations are proposed in this paper for

$331 \quad$ ULCC and RULCC, respectively.

332 For ULCC matrix, the new DIF formula follows the structure of the CEB-FIP's equation, i.e.,

$$
D I F=\frac{\sigma_{d}}{\sigma_{s}}=0.0106\left(\frac{\dot{\varepsilon}_{\mathrm{c}}}{\dot{\varepsilon}_{s}}\right)^{\frac{1}{3}} \quad \dot{\varepsilon}_{d}>30 s^{-1}
$$

334 For rubberized ultra-lightweight cement composites, DIF takes the form as proposed by Ngo et al.

335 [42], considerring that the behaviour of ultra-lightweight cement composites is similar to that of

336 high strength concrete. It should be noted that $\beta$ and $\gamma$ are considered as functions of the rubber

337 replacement ratio $R$, so that the effect of the ratio can be properly included in the formula. This is

338 different from the CEB-FIP equation that can not consider the rubber content. In Chen's model,

339 the compressive strength and $R$ are both included in the formula. Althought the formula can

340 consider the effect of the rubber replacement ratio and matrix strength through a rather complex

341 calculation process, the dimensions of the formula are not consistance, which may require further

342 revaluation. Considering of abovementioned factors and take advantages of the tests results of this

343 study, a modified DIF formula is proposed below.

$$
D I F=\frac{\sigma_{d}}{\sigma_{s}}=\beta \times \lg \left(\frac{\dot{\varepsilon}_{\mathrm{c}}}{\dot{\varepsilon}_{s}}\right)-\gamma \quad \dot{\varepsilon}_{d}>30 s^{-1}
$$

345 where, $\beta$ and $\gamma$ are defined as a linear function of rubber replacement ratio $R$ in volume fraction,

346 i.e., $\beta=8.121 R+1.458, \gamma=54.587 R+7.250$, where the constants are obtained from the experimental

347 results through regression. The DIF of RULCC calculated from Eq.(5) is larger than that of normal

348 concrete, which indicates that RULCC is more sensitive to strain rate. ULCC has more air bubbles

349 and smaller elastic modulus, leading to a higher deformation capacity and energy absorption per350 formance. 


\subsection{Verification of the proposed model}

352 Table 6 presents the DIFs calculated by the CEB-FIP model (DIF $\left.{ }_{\mathrm{CEB}}\right)$, Chen's model (DIF ${ }_{[26]}$ ),

353 Ngo et al.'s model ( $\left.\mathrm{DIF}_{[42]}\right)$ and the newly proposed model (DIF $\left.\mathrm{Dre}\right)$ in this paper. From the table,

354 it is shown that the average values of $\mathrm{DIF}_{\text {test }} / \mathrm{DIF}_{\mathrm{CEB}}, \mathrm{DIF}_{\text {test }} / \mathrm{DIF}_{[21]}, \mathrm{DIF}_{\text {test }} / \mathrm{DIF}_{[40]}, \mathrm{DIF}_{\text {test }} / \mathrm{DIF}_{\text {pre }}$

355 are $1.12,0.96,1.22$ and 0.99 , respectively, with standard deviations of $0.14,0.11,0.16$ and 0.05 .

356 It can also be seen that using of CEB-FIP and Ngo et al.'s model directly may underestimate the

357 DIFs for the ULCC and the RULCC. The newly proposed model provides better prediction to the

358 DIFs with the smallest standard deviations for both the ULCC and the RULCC. Chen's model

359 gives reasonably accurate predictions for the ULCC without added rubber, but with slightly larger

360 deviation. Fig.14 plots and compares the DIF curves using all the above models for the ULCC and

361 the RULCC groups. It should be noted that the newly proposed DIF formula is a function of the

362 strain rate and the rubber replacement ratio $R$, which is different from the CEB-FIP prediction that

363 takes exponential function for all types of concrete when the strain rate is beyond $30 \mathrm{~s}^{-1}$. It can be

364 seen from the comparisons that all the experimental results fall within the two curves predicted by

365 the newly proposed model. To further verify the propose model, further new independent impact

366 tests on the RULCC with different rubber replacement ratios arranged from $0 \%$ to $20 \%$ were con-

367 ducted. Figure 14 also compares the formulas with the additional independent test data in the DIF-

368 strain rate curves, which again demonstrates that the proposed DIF model can provide accurate 369 predictions and potentially be used in dynamic design of RULCC in the future. 
Table 6 Verification of DIFs by the existing models

\begin{tabular}{|c|c|c|c|c|c|c|c|c|c|c|c|}
\hline MIX ID & $\begin{array}{c}\sigma_{s} \\
(\mathrm{MPa})\end{array}$ & $\begin{array}{r}\sigma_{d} \\
(\mathrm{MPa})\end{array}$ & $\mathrm{DIF}_{\text {test }}$ & $\mathrm{DIF}_{\mathrm{CEB}}$ & $\begin{array}{l}\mathrm{DIF}_{\text {test }} / \\
\mathrm{DIF}_{\mathrm{CEB}}\end{array}$ & $\operatorname{DIF}_{[26]}$ & $\begin{array}{l}\mathrm{DIF}_{\text {test }} / \\
\mathrm{DIF}_{[26]}\end{array}$ & $\mathrm{DIF}_{[42]}$ & $\begin{array}{l}\mathrm{DIF}_{\text {test }} / \\
\mathrm{DIF}_{[42]}\end{array}$ & $\mathrm{DIF}_{\text {pre }}$ & $\begin{array}{l}\mathrm{DIF}_{\text {test }} \\
\mathrm{DIF}_{\text {pre }}\end{array}$ \\
\hline \multirow{4}{*}{$\mathrm{R} 0-0$} & \multirow{4}{*}{52.2} & 79.7 & 1.53 & 1.76 & 0.87 & 1.69 & 0.91 & 1.64 & 0.93 & 1.55 & 0.99 \\
\hline & & 88.7 & 1.70 & 1.96 & 0.87 & 1.87 & 0.91 & 1.81 & 0.94 & 1.73 & 0.98 \\
\hline & & 96.4 & 1.85 & 2.06 & 0.90 & 1.96 & 0.94 & 1.89 & 0.98 & 1.82 & 1.02 \\
\hline & & 100.8 & 1.93 & 2.19 & 0.88 & 2.08 & 0.93 & 2.00 & 0.97 & 1.94 & 0.99 \\
\hline \multirow{4}{*}{$\mathrm{R} 5-0$} & \multirow{4}{*}{36.8} & 76.3 & 2.07 & 1.74 & 1.19 & 1.87 & 1.11 & 1.63 & 1.27 & 2.11 & 0.98 \\
\hline & & 91.2 & 2.48 & 1.92 & 1.29 & 2.06 & 1.20 & 1.78 & 1.39 & 2.35 & 1.06 \\
\hline & & 93.7 & 2.55 & 2.05 & 1.24 & 2.19 & 1.16 & 1.88 & 1.36 & 2.51 & 1.02 \\
\hline & & 95.8 & 2.60 & 2.17 & 1.20 & 2.31 & 1.13 & 1.98 & 1.31 & 2.65 & 0.98 \\
\hline \multirow{4}{*}{ R10-0 } & \multirow{4}{*}{27.3} & 49.6 & 1.82 & 1.82 & 1.00 & 2.21 & 0.82 & 1.70 & 1.07 & 2.15 & 0.85 \\
\hline & & 62.1 & 2.27 & 1.95 & 1.16 & 2.35 & 0.97 & 1.80 & 1.26 & 2.34 & 0.97 \\
\hline & & 65.0 & 2.38 & 2.08 & 1.14 & 2.50 & 0.95 & 1.90 & 1.25 & 2.54 & 0.94 \\
\hline & & 74.6 & 2.73 & 2.19 & 1.25 & 2.62 & 1.04 & 1.99 & 1.37 & 2.69 & 1.01 \\
\hline \multirow{4}{*}{ R15-0 } & \multirow{4}{*}{23.6} & 49.4 & 2.09 & 1.82 & 1.15 & 2.36 & 0.89 & 1.69 & 1.24 & 2.07 & 1.01 \\
\hline & & 50.3 & 2.13 & 1.95 & 1.09 & 2.52 & 0.85 & 1.80 & 1.18 & 2.32 & 0.92 \\
\hline & & 56.8 & 2.41 & 2.10 & 1.15 & 2.69 & 0.90 & 1.92 & 1.26 & 2.56 & 0.94 \\
\hline & & 65.3 & 2.77 & 2.18 & 1.27 & 2.80 & 0.99 & 1.99 & 1.39 & 2.71 & 1.02 \\
\hline \multirow{4}{*}{ R20-0 } & \multirow{4}{*}{20.7} & 40.8 & 1.97 & 1.79 & 1.10 & 2.48 & 0.79 & 1.67 & 1.18 & 1.93 & 1.02 \\
\hline & & 46.8 & 2.26 & 1.92 & 1.18 & 2.65 & 0.85 & 1.78 & 1.27 & 2.22 & 1.02 \\
\hline & & 53.7 & 2.59 & 2.05 & 1.26 & 2.82 & 0.92 & 1.89 & 1.37 & 2.48 & 1.04 \\
\hline & & 57.4 & 2.77 & 2.21 & 1.25 & 3.02 & 0.92 & 2.01 & 1.38 & 2.77 & 1.00 \\
\hline Mean. & & & & & 1.12 & & 0.96 & & 1.22 & & 0.99 \\
\hline Std. & & & & & 0.14 & & 0.11 & & 0.16 & & 0.05 \\
\hline
\end{tabular}

\footnotetext{
* Corresponding author. Tel: +86 755-86975402; Fax: +86 755-26732850; Emails: suill@ szu.edu.cn; j.ye@lancaster.ac.uk
} 


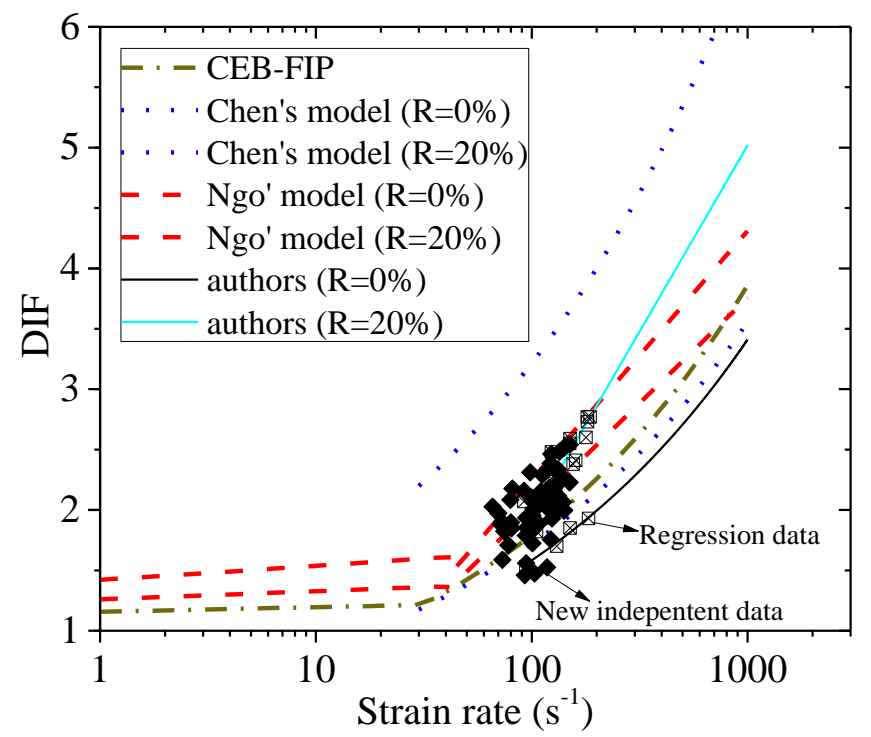

\section{Conclusions}

Figure.14 Proposed DIF model v.s. existing DIF models

This paper develops a novel ultra-lightweight high ductility cement composite (RULCC) with added low content of PE fibers $(0.7 \%)$ and different amount of rubber powder. The paper investigates the dynamic behavior of the RULCC based on the Split Hopkinson Pressure Bar tests and proposes modified equations to predict the Dynamic Increasing Factor (DIF) of the material. The following conclusions have been made on the basis of this study.

(1) The novel rubberized ultra-lightweight cement composite (RULCC) has a low density of $1450 \mathrm{~kg} / \mathrm{m}^{3}$ with high compressive strength of $52.2 \mathrm{MPa}$. The RULCC incorporated with low PE fiber content $0.7 \%$ (R0-0.7PE) exhibits 3\%-4\% tensile strain capacity, while that with another $10 \%$ added rubber powder (R10-0.7PE) could still have a strength of $24.9 \mathrm{MPa}$, but an increase of tensile strain up to 4-5\%, showing its high ductility performance. Multiple micro cracking behavior can be achieved in the RULCC. Compared to the conventional Engineering Cementitious Concrete (ECC) with $2 \%$ polymer fibers, RULCC can save $65 \%$ fiber content in volume which could be an economic solution for future applications.

(2) The static compressive strength of the RULCC decreases with the increase of rubber powder content. The reduction in the strength are the results of the lower elastic modulus of the rubber powder and the weak bond strength between the rubber particles and cement composite. The elastic modulus of the RULCC is much lower than that of normal concrete because of lower elastic modulus of FAC and absent of coarse aggregates.

* Corresponding author. Tel: +86 755-86975402; Fax: +86 755-26732850; Emails: suill@ szu.edu.cn; j.ye@ @lancaster.ac.uk 
(3) The SHPB compressive test shows that the rubber powder particle (less than $10 \%$ in volume) can improve the impact resistance of ULCC. The dynamic compressive strength decrease gradually as the rubber content in the composites increases. Compared to the materials without added rubber, the specimens exhibit better energy absorption performance. The enclosed areas in stress-strain curves of the RULCC groups increase significantly. Low content PE fiber (0.7\%) in cement composite can maintain integrity of the concrete and considerably increase the DIFs, due to the bridging effect of PE fiber. RULCC is more sensitive to strain rate, compared to normal concrete, lightweight aggregate concrete and high strength concrete.

(4) This paper proposes an effective model considering the strain rate effects and rubber replacement ratio $R$ to predict the DIFs. The proposed model provides improved predictions of DIFs for ULCC and RULCC, when compared to CEB-FIP, Chen's and Ngo et al.'s model. The newly proposed equations can be used to predict the DIFs of the novel RULCC subjected to impact.

\section{Acknowledgement}

The authors would like to acknowledge the research grant received from the National Natural Science Foundation of China (NSFC, No.51708360, 51978407), Innovative Project Funded by Ministry of Guangdong Province Education Office (No.2017KTSCX164), Shenzhen Basic Research Project (NO. JCYJ20180305124106675). The authors also would like to acknowledge Professor Liu Laibao from Xinan University of Technology for providing the rubber powder materials and Professor Dong Zhijun for providing SHPB test facility.

\section{References}

[1] Yingwu Zhou, Xiaoming Liu, Feng Xing, Hongzhi Cui, Lili Sui; Axial compressive behavior of FRP-confined lightweight aggregate concrete: An experimental study and stress-strain relation model, Construction and Building Materials, Vol. 119, 1-15, 2016.

[2] Tommy Yiu Lo, Hongzhi Cui, Shazim Ali Memon, Takafumi Noguchi, Manufacturing of sintered lightweight aggregate using high-carbon fly ash and its effect on the mechanical properties and microstructure of concrete, Journal of Cleaner Production, Vol. 112, 1, 753-762, 2016.

[3] Zhenyu Huang, Krishnan Padmaja, Shan Li, J.Y. Richard Liew, Mechanical properties and microstructure of ultra-lightweight cement composites with fly ash cenospheres after exposure to high temperatures, Construction and Building Materials,2018;164:760-774.

[4] Z.Y. Huang, F. Wang, Y.W. Zhou, L.L. Sui, P. Krishnan, J.Y.R. Liew, A novel, multifunctional, floatable, lightweight cement composite: development and properties, Mater. 11 (10) (2018) 20432062. 
[5] Derek Kramar, Vivek Bindiganavile, Impact response of lightweight mortars containing expanded perlite, Cem. Concr. Compos. 37 (2013) 205-214.

[6] Remzi Sahin, Ramazan Demirbog a, Habib Uysal, Rüstem Gül, The effects of different cement dosages, slumps and pumice aggregate ratios on the compressive strength and densities of concrete, Cem. Concr. Res. 33 (8) (2003) 1245-1249.

[7] JGJ 51-02. Technical specification for lightweight aggregate concrete. Beijing: China Academy of Building Research; 2002.

[8] CEB. CEB-FIP Model Code 2010-First Complete Draft, vol. 1. Lausanne, Switzerland. Committee Euro-International du Beton; 2010.

[9] BS, EN 13055. Lightweight aggregates, in part 1: Lightweight aggregates, Lightweight aggregates for concrete, mortar and grout. London: British Standards Institution; 2016.

[10] ASTM, C 213R-14. Guide for structural lightweight aggregate concrete. West Conshohocken (PA): ASTM International; 2014.

[11] ASTM, C 330-17. Standard specification for lightweight aggregates for structural concrete. West Conshohocken (PA): ASTM International; 2017.

[12] H.Z. Cui, T.Y. Lo, S.A. Memon, F. Xing, X. Shi, Analytical model for compressive strength, elastic modulus and peak strain of structural lightweight aggregate concrete, Constr. Build. Mater. 36 (2012) 1036-1043.

[13] M.H. Zhang, O.E. Gjorv, Mechanical properties of high-strength lightweight concrete, ACI Mater. J. 88 (3) (1991) 240-247.

[14] Z.Y. Huang, J.Y.R. Liew, W. Li, Evaluation of compressive behavior of ultra-lightweight cement composite after elevated temperature exposure, Constr. Build. Mater. 148 (2017) 579-589.

[15] Z.Y. Huang, J.Y.R. Liew, Nonlinear finite element modelling and parametric study of curved steel-concrete-steel double skin composite panels infilled with ultra-lightweight cement composite, Constr. Build. Mater. 95 (2015) 922-938.

[16] T.A. Holm, T. Bremner, J.B. Newman, Concrete brige decks: lightweight aggregate concrete subject to severe weathering, Concr. Int. 6 (6) (1984) 49-54.

[17] Qingxu Jin, Victor C. Li, Development of lightweight engineered cementitious composite for durability enhancement of tall concrete wind towers, Cement and Concrete Composites, 96, 2019, 87-94.

[18] Z.Y. Huang, J.Y. Wang, J.Y.R. Liew, P. Marshall, Lightweight steel-concrete-steel sandwich shell subject to punching shear. Ocean Eng. 102 (2015) 146-161.

[19] K.S. Chia, X.M. Liu, J.Y.R. Liew, M. H. Zhang, Experimental study on creep and shrinkage of high-performance ultra lightweight cement composite of 60MPa. Struct. Eng. Mech. 50 (5) (2014), 635-652.

[20] Y.P. Wu, J.Y. Wang, P.J. M. Monteiro, M.H. Zhang, Development of ultralightweight cement composites with low thermal conductivity and high specific strength for energy efficient buildings. Constr. Build. Mater. 87 (2015) 100-112.

[21] Z.Y. Huang, J.Y.R. Liew, Compression resistance of steel-concrete-steel composite wall with J-hook connectors. J. Constr. Steel Res. 124 (2016) 142-162. 
[22] Z.Y. Huang, J.Y. Wang, J.Y.Richard Liew and Peter Marshall. Lightweight steel-concretesteel sandwich shell subject to punching shear. Ocean Eng 2015; 102: 146-161.

[23] Z.Y. Huang, J.Y.R. Liew, Structural behaviour of steel-concrete-steel sandwich composite wall subjected to compression and end moment, Thin Wall. Struct. 98 (2016) 592-606.

[24] K.M.A. Sohel, J.Y.R. Liew, Behavior of steel-concrete-steel sandwich slabs subject to impact load. J. Constr. Steel Res. 100 (2014) 163-175.

[25] D. Fedroff, S. Ahmad, B.Z. Savas, Mechanical properties of concrete with ground waste tire rubber, Trans. Res. Rec. 1532 (1996) 66-72.

[26] G.X. Chen, Impact resistance research on rubberized concrete, Master's Degree Thesis. (2011) (in Chinese).

[27] M.A.E.M. Ali, A.M. Soliman, M.L. Nehdi, Hybrid-fiber reinforced engineered cementitious composite under tensile and impact loading, Mater. Design. 117 (2017) 139-149.

[28] M. Nili, V. Afroughsabet, Combined effect of silica fume and steel fibers on the impact resistance and mechanical properties of concrete. Int. J. Impact Eng. 37 (8) (2010) 879-886.

[29] T. Gupta, R.K. Sharma, S. Chaudhary, Impact resistance of concrete containing waste rubber fiber and silica fume. Int. J. Impact Eng. 83 (2015) 76-87.

[30] F. Liu, G.X. Chen, L. J. Li, Y.C. Guo, Study of impact performance of rubber reinforced concrete, Constr. Build. Mater. 36 (2012) 604-616.

[31] W.H. Feng, F. Liu, F. Yang, L.J. Li, J. Li, Experimental study on the effect of strain rates on the dynamic flexural properties of rubber concrete, Constr. Build. Mater. 224 (2019) 408-419.

[32] A.O. Atahan, U.K. Sevim, Testing and comparison of concrete barriers containing shredded waste tire chips, Mater. Lett. 62 (21-22) (2008) 3754-3757.

[33] S. HentZ, F.V. Donzé, L. Daudeville, Discrete element modelling of concrete submitted to dynamic loading at high strain rates, Comput. Struct. 82 (29) (2004) 2509-2524.

[34] M. Adamu, B.S. Mohammed, M.S. Liew, Effect of crumb rubber and nano silica on the creep and drying shrinkage of roller compacted concrete pavement, Int. J. Goe. 15 (47) (2018) 58-65.

[35] ACI Committee 544, State-of-the-art report on fiber reinforced concrete, American Concrete Institute, Detroit, 1996 Report 544.1R-96.

[36] D.Y. Yoo, N. Banthia, Impact resistance of fiber-reinforced concrete - A review. Cement Concrete Comp. 104 (2019) 103389.

[37] Y.C. Guo, J.H. Xie, W.Y. Zheng, J.L. Li, Effects of steel slag as fine aggregate on static and impact behaviours of concrete, Constr. Build. Mater. 192 (2018) 194-201.

[38] ASTM, C 39/C 39M-18. Standard Test method for compressive strength of cylindrical concrete specimens. West Conshohocken (PA): ASTM International; 2017.

[39] JSCE, Recommendations for Design and Construction of High-Performance Fiber Reinforced Cement Composites with Multiple Fine Cracks, Japan Society of Civil Engineers, Tokyo, Japan, 2008. 
[40] J. Hopkinson, On the rupture of iron wire by a blow, in: B. Hopkinson (Ed.), Original papersby the late John Hopkinson, Scientific Papers, Cambridge Univ. Press, 1901. 316-320.

[41] Y.W. Zhou, B. Xi, K.Q. Yu, et al. Mechanical properties of hybrid ultra-high performance engineered cementitous composites incorporating steel and polyethylene fibers, Mater. 11 (8) (2018) 1448-1468.

[42] T. Ngo, P. Mendis, T. Krauthammer, Behavior of ultrahigh-strength prestressed concrete panels subjected to blast loading, J. Struct. Eng. 2007, 133 (11) (2007) 1582-1590.

[43] Xiong B, Demartino C, Xiao Y. High-strain rate compressive behavior of CFRP confined concrete: Large diameter SHPB tests. Construction and Building Materials, 2019, 201:484-501.

[44] H.Y. Zhou, A. M. Brooks., D. Hanna, B. Salarieh. Thermal and mechanical properties of cementitious for additive construction of energy-saving habitats, Earth and Space 2018. Cleveland OH, ASCE, (2018) 600-610. 